\title{
Social Preferences, Skill Segregation, and Wage Dynamics
}

\author{
ANTONIO CABRALES \\ Universidad Carlos III de Madrid and CEPR \\ ANTONI CALVÓ-ARMENGOL ${ }^{\dagger}$ \\ ICREA, Universitat Autònoma de Barcelona, and CEPR \\ and \\ NICOLA PAVONI \\ University College London and Institute for Fiscal Studies
}

\begin{abstract}
We study the earning structure and the equilibrium assignment of workers to firms in a model in which workers have social preferences, and skills are perfectly substitutable in production Firms offer long-term contracts, and we allow for frictions in the labour market in the form of mobility costs The model delivers specific predictions about the nature of worker flows, about the characteristics of workplace skill segregation, and about wage dispersion both within and across firms We show that long-term contracts in the presence of social preferences associate within-firm wage dispersion with novel "internal labour market" features such as gradual promotions, productivity-unrelated wage increases, and downward wage flexibility These three dynamic features lead to productivity-unrelated wage volatility within firms
\end{abstract}

\section{INTRODUCTION}

There is a widespread perception within organizations that equity inside the firm is an important consideration for its smooth and efficient functioning. Just to give an example, ${ }^{1}$ Bewley (1999) provides a number of revealing quotes from managers about the disruptive effects of lack of equity on the job. Some $78 \%$ of the businesspeople whom he asked about internal equity said that it is important for internal harmony and morale. ${ }^{2}$ Morale meant "cooperativeness, happiness or tolerance of unpleasantness, and zest for the job". ${ }^{3}$ He also shows that an important consequence of internal inequity in firms is turnover. ${ }^{4}$

Economists have realized, since at least Keynes, that concerns for equity in the workplace should have implications for the labour market and the general economy. ${ }^{5}$ One particularly

1 Other papers that offer survey evidence on the importance of equity concerns in organizations are Blinder and Choi (1990), Bewley (1995), Agell and Lundborg (1995, 2003), and Campbell and Kamlani (1997)

2 Bewley (1999, table 65$)$

3 Bewley (1999, p 42)

4 Bewley (1999, table 65$)$

5 "Any individual or group of individuals, who consent to a reduction of money wages relatively to others, will suffer a relative reduction in real wages, which is a sufficient justification for them to resist it On the other hand it would be impracticable to resist every reduction of real wages, due to a change in the purchasing-power of money, which affects all workers alike; and in fact reductions of real wages arising in this way are not, as a rule, resisted unless they proceed to an extreme degree" (Keynes, 1936, ch 2) 
important implication already noted by Keynes (1936) is that concerns for relative pay would lead to wage stickiness and would make quantity adjustments, and thus unemployment, more likely.

But only very few papers have gone beyond, to explore the wider implications for withinfirm wage structure and the labour market of these equity concerns. An important exception is Robert Frank, who in his seminal (1984) paper showed that workers can be paid a wage that differs from marginal productivity when they care about the wages of other workers.

A simple static environment such as that of Frank has important limitations, though. For example, his framework is unable to link inter-firm skill segregation to other typical labour market features, such as worker flows: quits and lay-offs. Our paper brings these early attempts one step further and studies the labour market implications of social preferences in a richer dynamic environment, with uncertainty and frictions. Ours is probably the first model to characterize dynamic contracts in the presence of social preferences in a competitive labour market.

By introducing concerns for equity inside the firm in a dynamic contracting setting, we not only provide new and richer answers to previous issues, ${ }^{6}$ but also aim to address new questions, such as "What are the implications of social preferences for wage dispersion within the firm and for the evolution of wages over time?"

In our equilibrium model, the internal wage structure embeds the external competitive pressure along with the optimal adjustment to internal envy costs, themselves related to internal firm skill composition. These complex interactions lead to a rich set of empirical implications, both inside the firm and for the external labour market. For instance, we find wage variations that are not connected with changes in productivity, inter-firm segregation of workers by their relative productivity, and wage cuts. We show that these implications, many of them somewhat hard to reconcile with standard models, are satisfied in the data. It is true that, taken one by one, these facts can be explained with more standard models. ${ }^{7}$ But, in the first place, we provide a unified explanation for all of them. And for some of these observations, our explanation brings a new perspective, thus making them empirically distinguishable from the alternative explanations. For example, in our model, the wage may increase even when worker expected productivity actually declines, something not accounted for by alternative explanations such as insurance motives. Moreover, as we will explain below, our model has different predictions regarding the timing and correlation between wage changes and worker flows from those of more common models of skill segregation which rely on production complementarities (e.g. Kremer and Maskin, 1996).

The environment. We consider a labour market in which risk-neutral firms compete for risk-averse workers of heterogeneous quality. The efficiency units of workers' labour are perfect substitutes. That is, some workers are more productive/skilled than others, but workers of different skills are perfectly substitutable in some fixed proportions. Firms compete by offering long-term contracts. The firms can commit to the contracts, but the workers can always accept external offers. ${ }^{8}$ The quality of the workers is not perfectly observable ex ante, but their performance over time slowly reveals (with some noise) this quality. ${ }^{9}$

The novelty of the model is that workers have "social preferences", that is, their final utility is affected by that of others. This assumption is consistent with the evidence showing that preferences of individuals depend on their own material well-being, but also on that of others.

6 As we explain in detail a bit later, we also have implications for segregation by skill that are different from those in Frank's (1984) work

7 For instance, insurance motives can also disconnect productivity from wage changes, while production complementarities between workers of similar skill level are believed to be a source of workplace segregation

8 For example, workers cannot post a bond, which would enforce the commitment to stay in the current firm

9 This set-up borrows heavily from the model of Harris and Hölmström (1982), to which we often refer as a benchmark for comparing our analysis 
But which others? We assume that these comparisons do not span the whole population, but only individuals who work in the same firm and have had similar career histories within the firm. For any given worker and period, we call his reference group the set of individuals over whom his social preferences' comparisons take place in that period. We further assume that the reference group changes over time, as promoted individuals eventually exit the reference group. These assumptions incorporate the well-established notion in sociology and social psychology that group identification arises through active interaction and fades away over time when the interaction is not sustained (Coleman, 1990). ${ }^{10}$

Because real markets are not perfectly frictionless, we introduce a simple form of friction: moving (or hiring and training) costs. These costs will produce a countervailing force to external market pressures and internal envy costs and will enrich the set of predictions about labour market outcomes.

Overview of the results. Our analysis provides a complete picture of equilibrium contracts and workers' firm assignments over time. We provide a full characterization of this equilibrium by means of a recursive formulation. We complement our analytical description with a numerical computation for a simple, transparent, and easily replicable environment, where the main comparative statics are displayed.

Our first result is that in the absence of frictions and with social preferences, of however small strength, the equilibrium becomes skill-segregated; that is, firms hire only from one skill pool. ${ }^{11}$ The externality driving segregation is different from the one in models of, say, racial segregation. We deal here with a pecuniary externality, that is, high-skilled types do not separate from low-skilled types because they intrinsically dislike them. They do it, rather, because the market tends to produce different material pay-offs for both. We next examine the implications of non-vanishing moving costs.

When moving costs between firms are low, heterogeneous productivity leads to widespread workplace skill segregation, and the whole market wage dispersion is explained by differences between firms. With intermediate levels of mobility costs, segregation is more moderate, and wage dispersion arises both within and across firms. For high levels of moving costs, the whole wage dispersion is within the firm, and it becomes zero when the moving costs are sufficiently high. We show that within-firm wage dispersion is associated with "internal labour market" features such as gradual promotions, productivity-unrelated wage increases, and downward wage flexibility.

These results arise from an interplay between risk preferences, social preferences, and market competition. We examine these mechanisms separately.

We first discuss the implications in our model of the combination of risk preferences with our commitment structure. When there are neither social preferences nor frictions, the equilibrium labour contracts are as in Harris and Hölmström (1982), that is, wage payments are constant over time for a given observational type (for insurance reasons), and they change when the observational type changes. The presence of frictions in the market implies (in the absence of social preferences) that when higher types are revealed, their wage changes less than in the absence of such frictions. Because of these frictions, workers remain employed with the firm that first hires them; that is, there are no flows of workers in the labour market.

Next, we consider the effect of social preferences and frictions. As before, the frictions make it costly for workers to move between firms when their types are revealed. On the other hand, competitive pressure forces wages to be different for different (perceived) skill types. Thus, if workers of different types (who receive different wages) stay together, social preferences generate

10 See also van Dijk and van Winden (1997)

11 In a sense, we can argue that social preferences operate here as a kind of "equilibrium-refinement" The advantage of this way of refining equilibria is that the pay-off perturbation is economically and empirically well motivated 
a loss in utility for some of them. To compensate for the disutility, the firm can increase the wages of the lower types. ${ }^{12}$ This is what we refer to as productivity-unrelated wage increases. The firm can also modify the composition of its workforce by letting some of the current workers leave and thus achieve a more homogeneous (in terms of perceived skills) workers' pool. The firm now faces a trade-off between productivity-unrelated wage increases and skill segregation, and the size of the frictions determines the optimal solution to this trade-off.

The presence of frictions entices the market participants to find imaginative ways around them. Firms exploit the precise nature of the externality in order to reduce its distortionary effects. Recall that the social externality spans each worker's reference group, which is not the whole set of firm employees, but only those that enjoyed similar circumstances in the near past. Then, since promotions modify the composition of the reference group, gradual promotions become a new tool (in addition to productivity-unrelated wage increases) to accommodate the adverse effects of social preferences. Rather than promoting an individual as soon as he is discovered to be of a high type, we show it is optimal to propose contracts that give a "smaller" promotion until his former peers "forget" him and then promote him further later in the future. ${ }^{13}$ The dynamics of wages result from the complex interplay of the history of individual productivity, market competition, and inter-temporal composition of reference groups.

An additional implication of assuming "history-dependent" reference groups is that wage schedules may be downward flexible. When some individuals' performances have started to differ only recently from others, there are some productivity-unrelated wage increases, raising the salaries of low types. Once the high types have disappeared from the reference group, the salary of the low types can fall back to "normal".

Literature on wage inequality and skill segregation. Our model generates well-defined properties on the dispersion of wages, both within and across firms, and on how such characteristics change with few key parameters of the model. A wide body of research has observed a connection between the increase in inter-firm wage inequality and the increase of ability sorting. ${ }^{14}$

Theoretical explanations for this evidence usually resort to the introduction of some form of complementarities between individuals of the same skill levels. ${ }^{15}, 16$ We depart from this by not postulating any form of production complementarities between workers' types. The externality that arises between workers is of a pecuniary nature. It arises because market outcomes favour more productive workers, and individuals are averse to inequalities in their own reference group. ${ }^{17}$ Our model has different predictions regarding the timing and correlation between wage changes and worker flows from those of models with complementarities. For example, let us compare our model's predictions with those of Kremer and Maskin (1996). Consider the situation where a pool of high-productivity workers receives a wage increase inducing an outflow

12 Because of competitive pressures, there is no room to decrease wages for the higher types

13 Because of insurance effects for the high type, this gradual promotion is second best We show that the firm balances this inefficiency with the social concerns to choose an optimal (gradual) promotion path

14 See, for example, Brown and Medoff (1989), Davis and Haltinwanger (1991), Kramarz, Lollivier and Pelé (1996), Kremer and Maskin (1996), Abowd, Kramarz and Margolis (1999), Acemoglu (1999), Burgess, Lane and McKinney (2004), and Dunne, Foster, Haltiwanger and Troske (2004)

15 Good examples of these explanations are de Bartolomé (1990), Bénabou (1993), Kremer and Maskin (1996), and Saint-Paul (2001) The theoretical papers of Legros and Newman (2002, 2004) identify the minimal conditions for such positive sorting

16 A notable exception is Acemoglu (1999), who studies how a skill-biased technological shock or an increase in the supply of skills affects unemployment and the sorting of workers across firms in a labour market with adverse selection In our model, information is imperfect but symmetric

17 There are other models of segregation that rely on group externalities Seminal works in this area are Becker (1957) and Schelling (1971) Contrary to our paper, in that literature the individuals have an intrinsic like or dislike of workers in their or other groups In our case, the spillover is related only to the market outcome High and low types would live happily together if wages were equal 
of workers of unknown productivity. In our model, the flow would happen after the increase in productivity. In the Kremer and Maskin model, a similar phenomenon could happen. It might be the case that some low-productivity workers are fired and perhaps some more productive workers would take their place. This is likely to induce an increase in wage. Notice, however, that the wage increase in their model is induced by the change in worker composition. Worker flow must hence happen before the increase in wage. The two models can be distinguished based on the different timing of the combined occurrence of worker outflows and wage increases within the firm.

An important observation in comparing our work with the aforementioned papers is that their empirical evidence deals mainly with ex-ante observable skill differences. We, on the other hand, only make predictions about ex-post or unobservable skill heterogeneity. That is, the kind of increasing wage differential that we can explain occurs after controlling for observables such as education, sex, religion, and industry. We believe this is a strength of our work, since much of the recent increase in wage inequality happens precisely after controlling for observables. ${ }^{18}$ Acemoglu (2002) notes, in fact, that "Analysis of the determinant of residual inequality... remains a major research area".

It is perhaps fair to say that the evidence of Kramarz et al. (1996) and Kremer and Maskin (1996) on occupation mobility does not necessarily indicate that ex-ante observable skills are the key determinant for the increased wage correlation within firms either. Kremer and Maskin themselves recognize (at p. 18) that "... worker classification... is somewhat problematic as a measure of skill, since it reflects characteristics of the job, as well as of the worker". In fact, in most cases a promotion-which would happen in our model as a consequence of an ex-post revelation of the worker's type-gets recorded as an occupational change. ${ }^{19}$ For our purposes, it is important to note that Acemoglu (1999) shows that in the Current Population Survey the sorting of workers across occupations increased between 1983 and 1993, where occupations are ranked according to the wage residuals, after controlling for worker observables such as education, sex, experience, and location (metropolitan dummy). Moreover, Burgess et al. (2004) use matched employed worker longitudinal data in the period 1986-1998 and find that the allocation of workers to jobs played a significant role in explaining within-group wage inequality. ${ }^{20}$

Literature on social preferences and the labour market. Research on social preferences originated in large measure to give account of the growing empirical and experimental evidence that human behaviour could not be explained only by the hypothesis of self-interested material pay-off maximization. For instance, contribution to public goods is higher than would be expected under purely selfish maximization. ${ }^{21}$ More importantly from our point of view, there are vast amounts of evidence that people reject lopsided offers in ultimatum bargaining games. ${ }^{22}$

18 Juhn, Murphy and Pierce (1993) and Katz and Autor (1999, section 24 ) measure between two-thirds and threefourths the contribution of the "residual" (within-group) inequality in explaining the total increase in wage dispersion over the last 25 years

19 For example, both Kremer and Maskin (1996) and Kramarz et al. (1996) distinguish between blue-collar and foreman workers The latter seems to be, however, the natural occupation that a blue-collar worker reaches as a consequence of a promotion

20 The evidence regarding the effect on US wages of firms' characteristics emphasized by Davis and Haltinwanger (1991), and on their importance in explaining wage inequality on top of workers' observable characteristics (e.g. Figure 2) can also be interpreted as (perhaps more indirect) evidence that the allocation of workers across firms is important in explaining residual wage inequality: "The tremendous magnitude of the rise in the size-wage gap indicates that sorting by worker ability across plants of different sizes probably increased over time" (pp 156-157) Abowd et al. (1999) complement such evidence by showing that, for France, most of the firm-size wage effect is due to person-effects differences, after controlling for education, sex, experience, seniority, and location (regional dummy) See also Dunne et al. (2004)

21 See Ledyard's (1995) survey on public goods in the Handbook of Experimental Economics

22 See Güth, Schmittberger and Schwarze (1982) and also Roth's (1995) survey on bargaining in the Handbook of Experimental Economics 
Several models have been proposed to account for these observations, ${ }^{23}$ and we refer to the excellent surveys of Fehr and Schmidt (2000b) and Sobel (2005) for a discussion. A feature that most of the models share is that individuals dislike pay-off inequality.

One innovation with respect to this literature is that we think explicitly about the set of individuals to which the utility comparisons apply. In our paper, the reference group for comparisons is a product of the collective employment history. Workers identify less with superiors than with co-workers at their same level or recently promoted. Akerlof and Kranton (2000) also relate identity with incentive problems. In their case, the agents' identification with a particular group gives them an incentive to exert effort, in a moral-hazard context. For us, the identification with a reference group creates disutility for individuals who earn less than the average in their reference group.

A few papers examine the implications for wages and the labour market of social preferences. Frank (1984) in his seminal paper shows that workers need not be paid their marginal productivity if people have preferences such that they care sufficiently strongly (and in a heterogeneous way) about relative pay-offs, liking to be paid better than others and disliking to be paid worse. The more productive people would be paid less than their marginal productivity as they got the "pleasure" of earning more than their colleagues. Similarly, the less productive people would be paid more than their marginal productivity so as to be compensated for the "suffering" of earning an inferior wage. ${ }^{24}$ Since our model is dynamic, we can account for a number of features of the empirical evidence that cannot be addressed by Frank's model. In addition, the fact that in his model some individuals have a preference for status (having a higher wage than others gives them extra utility) would induce the opposite of segregation by skill. ${ }^{25}$ Both of these features are shared with the work of Fershtman, Hvide and Weiss (2006). Rey-Biel (2002) and Fehr, Klein and Schmidt (2007) deal with contracting problems and social preferences in environments with hidden effort/moral hazard.

As one can readily see, social preferences produce a wide variety of effects that happen in well-specified circumstances, ranging from segregation by skill, to gradual promotion, productivity-unrelated wage increases and downward wage flexibility. Models with this richness allow for a better empirical fit with reality (if, as we expect, social preferences of this form are indeed present). They also suggest that labour and human resource economics can greatly benefit from incorporating behavioural factors in their standard set of tools.

Paper structure. Section 2 describes the dynamic labour market model. Section 3 presents the recursive formulation of the problem and states the equivalence with the market game of Section 2. All results are gathered in Section 4. Section 5 develops and implements numerically a three-period version of the general model and discusses comparative statics. In Section 6, we discuss our theoretical results in light of some of the widely known empirical findings. Section 7 concludes. Appendix A describes the recursive formulation in its most general form and establishes the equivalence between the market game in Section 2 and the simplified recursive formulation in Section 3. The proofs of the results stated in Section 4 are in Appendix B. Appendix C contains an exhaustive analysis of the value function of our model, while the solution to a parametric three-period model is developed in Appendix D. ${ }^{26}$

23 Bolton (1991), Rabin (1993), Levine (1998), Bolton and Ockenfels (2000), Fehr and Schmidt (2000a), and Charness and Rabin (2002)

24 Frank (1985) discusses many practical implications of this basic framework, such as the puzzling omnipresence of minimum wages, safety regulations, forced saving for retirement, and other labour market regulations These can be explained with his model as a way to compensate for the externality that is generated by the social preferences

25 On p 551 of Frank (1984), we find "wage contracts exist that will cause heterogeneous associations of individuals to form in which status-seeking indviduals transfer resources to others who care less about status"

26 Appendices $\mathrm{C}$ and D are available online at http://www restud com/supplementary asp 


\section{MODEL}

Time is discrete and indexed by $t=1, \ldots, T<\infty$.

Firms. For each period, there is a finite set $M_{t}$ of risk-neutral firms that enter the market, post an offer, and hire new workers. For simplicity, we assume that the $M_{t}$ s are disjoint, ${ }^{27}$ so that $M^{t}=\cup_{s=1}^{t} M_{s}$ is the set of firms that had the chance to make an offer at some date prior to $t$.

Firms that are active in the market collect profits at the end of each period. Firms discount at zero interest rate.

Workers and timing. Workers are risk averse and live for $T$ periods.

There is a continuum of workers in $[0,1]$ of two different types, $g(\mathrm{ood})$ workers and $b(\mathrm{ad})$ workers. Workers $g$ produce one unit of output per period with i.i.d. probability $p$ (and zero otherwise), while workers of type $b$ have no chance of producing good outcomes (their production is always zero). We denote by $\lambda \in(0,1)$ the number of workers of type $g$ in the population. Information about workers' types is imperfect but symmetric, as in Harris and Hölmström (1982).

In each period $t$, the timing of payment is as follows. The worker decides whether to stay in the firm or accept an outside offer. If the worker decides to stay in the firm, he receives the wage from his employer. ${ }^{28}$ He then produces (thereby possibly revealing his type). This new information is then used at the beginning of the next period by the entrant firms (the market) to make job offers and by the old firm to pay $t+1$ wages taking into account the labour market pressure.

Worker assignment. At each period $t$, the mapping $f_{t}:[0,1] \rightarrow M^{t} \cup\{0\}$ keeps track of the assignment of workers to firms. The case $f_{t}(i)=0$ corresponds to worker $i$ being unemployed.

Whenever a worker changes firm, he pays a fixed mobility cost $k \geq 0$. This can be interpreted as a moving or hiring cost.

Outputs and types. Firms learn about the workers' types by observing production outcomes of each period.

Consider some worker $i \in[0,1]$. Let $y_{t}^{i}=1$ if worker $i$ generates a positive output at $t$ (thus revealing he is of type $g$ ) and $y_{t}^{i}=0$ otherwise. We set $y_{0}^{i}=0$.

The quality of the worker is a crucial state variable of this problem. Let $q_{t}^{i}$ be the belief that a worker $i$ is of good type at the beginning of period $t$. By Bayes' rule, next period's quality value is $q_{t+1}^{i}=1$ if $y_{t}^{i}=1$, and

$$
q_{t+1}^{i}=\frac{q_{t}^{i}(1-p)}{q_{t}^{i}(1-p)+\left(1-q_{t}^{i}\right)}
$$

if $y_{t}^{i}=0$, with initial condition $q_{1}^{i}=\lambda$ for all $i{ }^{29}$

Contracts and contract offers. A long-term contract specifies a sequence of non-negative payments contingent on observed history, which includes worker-firm assignments, production, and types. There is full commitment from the firm on the terms of the contract.

27 The main advantage of this assumption is that we will not have to specify how old cohorts consider newly hired workers As a by-product, we also obtain an equilibrium refinement that allows us to link skill segregation to worker flows (see Proposition 3 and the following discussion in Sections 42 and 4 3)

28 We will see that, for insurance purposes, the worker may, in fact, receive (severance) payments from earlier employers as well

29 This stochastic structure of types implies that $q=1$ is an absorbing state This way we simplify the nature of contracts but the intuition carries over with a richer stochastic structure 
Let $h_{t}^{i}$ be agent $i$ 's individual history at the beginning of period $t$, after the period $t$ employer has been chosen. This history includes his observed productivity and list of past employers. Let $H$ be the set of all conceivable histories. For all $s \geq t$, denote by $H\left(h_{t} ; s\right)$ the set of histories starting from and including node $h_{t}$ until period $s$. In our model, individuals are identified by their histories. Let $\left(h_{t} \backslash f_{t}\right)$ be a shorter notation for history $h_{t}$ without specifying the workerfirm assignment at period $t$.

Definition 1. A feasible contract offer $W_{t}^{j}\left(h_{t} \backslash f_{t}\right)$ in period $t$ by firm $j \in M_{t}$ is a collection of mappings $w_{s}^{j}: H\left(h_{t} ; s\right) \times[0,1] \rightarrow \mathbb{R}_{+}$such that for all individuals and histories, $w_{s, i}^{j}\left(h_{s}\right)$ is the wage paid in period $s \geq t$ to worker $i$. Moreover, we assume that individuals with the same history receive the same wage.

Notice that we assume that firms cannot post contract offers that depend on the identity of the worker per se, but we allow them to depend on each past worker's employment history. From now on, and to simplify notation, we thus omit the worker index in the payment schedules.

At each period, all firms simultaneously post feasible contracts, taking as given previous offers.

Then, workers simultaneously decide whether to accept any new contract, to remain with the current employer at the previously agreed contract or to go unemployed.

Unemployment corresponds to an offer that pays zero under any present or future contingency. Let $\mathcal{W}=\left\{W_{t}^{j_{t}}(\cdot)\right\}_{t=1, \ldots, T}^{j_{t} \in M^{t} \cup\{0\}}$ be the whole set of contract offers.

Workers' strategies. Worker-firm assignments are determined by workers' decisions in any period. We represent the choice of worker $i$ by a sequence of functions $F_{t}^{i}(\cdot)$ of the form $F_{t}^{i}: H\left(h_{t} \backslash f_{t}\right) \rightarrow M^{t} \cup\{0\}$. Denote by $\mathbf{F}^{i}=\left\{F_{t}^{i}(\cdot)\right\}_{t=1}^{T}$ a complete sequence of such functions, which completely describes worker $i$ 's choice. Denote by $\mathcal{F}=\left\{\mathbf{F}^{i}(\cdot)\right\}_{i \in[0,1]}$ the whole set of workers' assignment sequences. ${ }^{30}$

Workers' (social) preferences. Notice that the set of contract offers $\mathcal{W}$ generates "total wage" schedules $w_{t}(\cdot): H \rightarrow \mathbb{R}$ defined as follows:

$$
w_{t}\left(h_{t}\right)=\sum_{j \in M^{t}} w_{t}^{j}\left(h_{t}\right)
$$

Let $\mathbf{w}=\left\{w_{t}(\cdot)\right\}_{t=1}^{T}$ be a set of "total wage" functions.

In addition to the utility they obtain from their own wage - their material pay-offs — workers also experience (dis)utility from the material pay-offs of firm mates in their reference group. More precisely, if we let $w_{t}\left(h_{t}\right)$ be the worker wage at node $h_{t}$, his instantaneous utility at period $t$ is

$$
u\left(w_{t}\left(h_{t}\right)\right)-A\left(\bar{w}_{t}\left(h_{t}\right)-w_{t}\left(h_{t}\right)\right)
$$

30 These functions are essential in generating individual histories Consider such a sequence Then, according to this sequence, at period 1, worker $i$ goes to firm $f_{1}(i)=F_{1}^{i}(0, \lambda)$ and the resulting individual history is $h_{1}^{i}=\{\emptyset\} \cup$ $\left(0, \lambda, f_{1}(i)\right)$ (recall that, by assumption, $h_{0}^{i}=\emptyset, y_{0}^{i}=0$, and $q_{1}^{i}=\lambda$ for all workers $i$ ) Then, production $y_{1}^{i}$ takes place, and firms update their beliefs to $q_{2}^{i}$ at the beginning of period 2 The firm assignment $f_{2}(i)$ of worker $i$ in period 2 is determined by the mapping $F_{2}^{i}\left(h_{2}^{i} \backslash f_{2}\right)=F_{2}^{i}\left(h_{1}^{i}, y_{1}^{i}, q_{2}^{i}\right)$, and so on until period $T$ Notice that since the unemployment offer is always in place, each worker's decision function $F_{t}^{i}(\cdot)$ is well defined at each node 
where $\bar{w}_{t}\left(h_{t}\right)$ is the maximum of $h_{t}$ 's firm mates' wages in his reference group, and $A(\cdot)$ is the function expressing the aversion to inequity. ${ }^{31}$

We assume that $A(\cdot)$ is zero-valued for $x \leq 0$, non-decreasing for $x>0$, continuously differentiable with $A^{\prime}(0)=0$, and convex. For instance, $A(x)=\alpha \max \{x, 0\}^{p}$, with $p>1$ and $\alpha \geq 0$. Under these conditions, $i$ experiences a disutility if and only if $h_{t}$ 's co-workers' highest wage is higher than his own. The material pay-off is described by a strictly concave and differentiable utility $u$.

Technically, ours is an extreme version of difference aversion models such as Bolton and Ockenfels (2000) and Fehr and Schmidt (2000a). In our model, the workers have no concern for inequality when they are the high earners. We have concentrated on aversion to inequality for low earners because that seems the stronger force empirically (see Fehr and Schmidt, 2000a; or Campbell and Kamlani, 1997, pp. 776-777). Plus, adding aversion to inequality for higherearning workers would lead to qualitatively similar results at the expense of some notational complication. There would be more significant differences if workers had a concern for status, that is, if they obtained extra utility from having a higher income than others. This is what Frank (1984) and Fershtman et al. (2006) assume. But this alternative assumption would induce the opposite of segregation by skill, which seems counterfactual. There are other models of social preferences where agents care about the actions or intentions of others (reciprocity). See, for example, Levine (1998) and Charness and Rabin (2002). These models would lead to significant differences with respect to our predictions only when the workers could choose the level of an effort variable, something that is beyond the scope of this paper.

We assume that the reference group of worker $h_{t}$ at period $t$, denoted by $R_{t}\left(h_{t}\right)$, corresponds to the set of $h_{t}$ 's co-workers of the same type (productivity and employer) as $h_{t}$ at period $t-1$. In other words, the reference group is not the whole set of firm employees, but only those that enjoyed similar circumstances in the near past. ${ }^{32}$ The reference group evolves through time as follows: the newly discovered high types exit the reference group they used to belong to in the period after their type is revealed. ${ }^{33}$ This captures the fact that our wage rises entail promotions within the firm, ${ }^{34}$ which is normally associated with a smaller intensity of interaction with previous co-workers, a key ingredient for group identification (Coleman, 1990). ${ }^{35}$

31 The total maximum wage $\bar{w}_{t}\left(h_{t}\right)$ to which a worker compares his own potentially incorporates payments from more than one firm This would seem a less natural target on which to base social preferences than, say, maximum wage from the current employer In equilibrium, however, only the unknown-type workers receive payments from more than one source (see Appendix A, footnote 74) And those workers only affect the total maximum wage $\bar{w}_{t}\left(h_{t}\right)$ when $\bar{w}_{t}\left(h_{t}\right)=w_{t}\left(h_{t}\right)$ But in that case making maximum wage equal to compensation from the current employer would make $\bar{w}_{t}\left(h_{t}\right)<w_{t}\left(h_{t}\right)$, so there would be no social concerns either Obviously, all the components of $w_{t}\left(h_{t}\right)$ are observed by the worker, so it is natural to consider all the sources of his compensation when computing his utility

32 One key advantage of this assumption about the reference group is that it isolates the contracts of individuals who enter the labour market at different dates In this way — since firms face constant returns to workers-we can model a labour market that functions indefinitely with finitely lived workers who have different dates of labour force entry As a matter of fact, the different cohorts may even have different sizes and different proportions of the various types of workers

33 Formally, if we denote by $R_{t}\left(h_{t}\right)$ the reference group of worker $h_{t}$ at $t$, we have

$$
R_{t}\left(h_{t}\right):=\left\{h_{t}^{\prime} \in f_{t-1}^{-1}\left(h_{t}\right): q_{t-1}^{\prime}=q_{t-1} \text { and } f_{t}^{\prime}=f_{t}\right\}
$$

where $q_{t-1}$ is the quality of worker $h_{t}$ in period $t-1$ and $f_{t}$ and $f_{t}^{\prime}$ are the period $t$ employer of worker $h_{t}$ and $h_{t}^{\prime}$ respectively (that is, the last entries in $h_{t}$ and $h_{t}^{\prime}$ ).

34 As Gibbs (1996) points out, promotions "are the primary means by which workers can increase their long-run compensation"

35 More generally, we could have assumed that the reference group of worker $i$ at period $t$ is equal to the set of $i$ 's co-workers of the same type as $i$ at periods $t-1$ to $t-r$ (for some fixed $r$ ), with possibly a different weight for each group This extension would considerably enlarge the state space, but all our results will hold with this more general specification as well 
Then, if $R_{t}\left(h_{t}\right)$ has positive mass, we have

$$
\bar{w}_{t}\left(h_{t}\right) \equiv \sup _{h_{t}^{\prime} \in R_{t}\left(h_{t}\right)} w_{t}\left(h_{t}^{\prime}\right)
$$

which defines a maximum wage schedule relevant for social preferences. We assume that $\bar{w}_{t}\left(h_{t}\right)=w_{t}\left(h_{t}\right)$ each time $R_{t}\left(h_{t}\right)$ has zero mass (including, obviously, the case when $R_{t}\left(h_{t}\right)=$ $\left.\left\{h_{t}\right\}\right)$. In equilibrium, rational agents compute the maximum wage function $\bar{w}_{t}(\cdot)$ using contract offers $\mathcal{W}$ and allocation rules $\mathcal{F}$. Let $\overline{\mathbf{w}}=\left\{\bar{w}_{t}\left(h_{t}\right)\right\}_{t=1}^{T}$ be the set of such maximum wage functions.

Given a $\mathbf{w}$ and a $\overline{\mathbf{w}}$, by choosing a set of assignment decision rules $\mathbf{F}$ workers assign a lifetime utility value to each node $h_{t} \backslash f_{t}$ in the usual way:

$$
U_{t}\left(h_{t} \backslash f_{t}, \mathbf{F} ; \mathbf{w}, \overline{\mathbf{w}}\right)=\mathbf{E}\left[\sum_{n=0}^{T-t} u\left(w_{t+n}\left(h_{t+n}\right)\right)-A\left(\bar{w}_{t}\left(h_{t+n}\right)-w_{t}\left(h_{t+n}\right)\right) \mid h_{t}\right] .
$$

Notice that the expectation operator is always well-defined since $\mathbf{F}$ specifies history $h_{t}$ which follows node $h_{t} \backslash f_{t}$, even for nodes that are not consistent with $\mathbf{F}$. When the other arguments are unambiguously defined, we will denote by $U_{t}\left(h_{t}\right)$ a function that associates a lifetime utility value to each node $h_{t} \in H$. Let $\mathbf{U}=\left\{U_{t}(\cdot)\right\}_{t=1}^{T}$ be a set of such functions.

Definition 2 (equilibrium). An equilibrium outcome is a tuple $[\mathcal{W}, \mathcal{F}, \mathbf{U}, \mathbf{w}, \overline{\mathbf{w}}]$ with the following properties:

(i) Profit maximization: $\mathcal{W}$ is such that, given the assignment $\mathcal{F}$, and $\mathcal{W} \backslash\left\{W_{t}^{j}\left(h_{t} \backslash f_{t}\right)\right\}$, each new firm $j \in M_{t}$ maximizes its expected profits at $W_{t}^{j}\left(h_{t} \backslash f_{t}\right)$;

(ii) Optimal assignment: $\mathcal{F}$ is such that each worker $i$ maximizes his lifetime utility (5) at $\mathbf{F}^{i}$ taking as given $\mathbf{w}$ and $\overline{\mathbf{w}}$;

(iii) Rational expectations: $\mathbf{w}$ and $\overline{\mathbf{w}}$ are computed from $\mathcal{W}, \mathcal{F}$ using (2), and (3) and (4), respectively.

Given $\mathbf{U}$, the optimal assignment strategies $\mathcal{F}$ can be constructed recursively as follows. Recall that $f_{t-1}(i)$ is the firm that employed worker $i$ at period $t-1$. Let $h_{t} \backslash f_{t}$ be a last-period node before firms make offers. At each such node, the worker decides to remain inside the firm or to leave by joining a competitor. Formally, worker $i$ solves

$$
U_{t}\left(h_{t} \backslash f_{t}\right)=\max _{\rho_{t} \in\{0,1\}} \rho_{t} U_{t}\left(h_{t-1}, q_{t}, f_{t-1}\right)+\left(1-\rho_{t}\right) U_{t}^{m}\left(h_{t} \backslash f_{t}\right),
$$

where $\rho_{t}=1$ (respectively $\rho_{t}=0$ ) stands for staying in (respectively leaving) the current firm. The expression $U_{t}^{m}\left(h_{t} \backslash f_{t}\right)$ corresponds to the best market offer, that is,

$$
U_{t}^{m}\left(h_{t} \backslash f_{t}\right)=\sup _{j \neq f_{t-1}(i), j \in M^{t} \cup\{0\}} U_{1}\left(h_{t-1}, q_{t}, j\right) .
$$

At equilibrium, $f_{t}(i)=f_{t-1}(i)$ if and only if the solution to (6) is $\rho_{t}=1$. Otherwise, the identity $f_{t}(i)$ of the new employer coincides with any of the best market offers available. ${ }^{36}$

We call the plan $\rho=\left\{\rho_{t}\left(h_{t}\right)\right\}_{t=1}^{T}$ the equilibrium retention policy. 


\section{OPTIMAL CONTRACTS: A RECURSIVE FORMULATION}

In this section, we show that the equilibrium allocation can be characterized recursively. This is so because firms' full commitment and the possibility of paying severance payments make the equilibrium constrained efficient. This is interesting because it makes the characterization of the equilibrium relatively simple, and it also simplifies the numerical computations of the equilibrium. Nevertheless, readers interested in the next section can proceed without much loss if they skip this one.

We now formulate a recursive constrained optimization problem. Then we show that the equilibrium of our game coincides with the solution of this optimization problem.

We first introduce some useful notations.

Good workers. Consider some worker $i$ that is known to be good at the beginning of time $t$ (that is, $q_{t}^{i}=1$ ). Then, from period $t+1 \mathrm{on}$, worker $i$ 's reference group includes only workers of good type. That is, for $s \geq t+1$, only workers $j$ with $q_{s}^{j}=1$ are in his reference group, and he is only in the reference group of such workers. Because of this and given our definitions of social preferences, there are no externalities across these workers and any other any more. Thus standard arguments imply that market competition and workers' risk aversion produce for all $s>t$ equilibrium wages for these workers that are equal across periods and production realizations (for insurance reasons), and across workers.

Workers of yet unknown type. Consider a firm $f$ designing the contingent payments to be effective at the end of period $t$. Workers that were not working in $f$ in the previous period do not belong to the reference group for workers already in $f$ at $t-1$ and vice versa. Thus, their contracts can be treated separately from the point of view of firm $f$. Similarly, as we argued before, workers $i$ with $q_{t-1}^{i}=1$ can be treated separately as well.

Thus we only need to focus on the characteristics of contracts for workers with $q_{t-1}^{i} \neq 1$ and who were employed in firm $f$ at $t-1$. We denote by $w_{g t}$ (respectively $w_{u t}$ ) the wage of such a worker when $y_{t}^{i}=1$ (respectively $y_{t}^{i}=0$ ). It follows from our definition that these payments are independent of the identity $i$ of the worker and that of his employer $f$.

The recursive formulation. Whenever no confusion is possible, and to simplify notation, we use letters without time subscripts to denote choice variables.

Let $q$ be the average quality of the current pool of workers within the same reference group (agents who had the same past history till the last period and enrolled in the same firm). Denote by $\pi$ the profits the firm makes out of this group.

Let $V_{t}(\pi, q)$ be the ex-ante (before production of the previous period realizes) utility of a worker who belongs to a reference group of average quality $q$, when the employer is expecting to make an ex-ante level of profits equal to $\pi$ when there are $T-t \geq 0$ periods before the end. Obviously, $V_{T} \equiv 0$. In general, we have

$$
V_{t}(\pi, q)=\max _{w_{u}, w_{g}, \rho, \pi_{u}, \pi_{g}}\left\{\begin{array}{c}
(1-p q)\left[u\left(w_{u}\right)-\rho A(\widetilde{w}(q))+V_{t+1}\left(\pi_{u}, q_{u}\right)\right] \\
+p q\left[u\left(w_{g}\right)+V_{t+1}\left(\pi_{g}, 1\right)\right]
\end{array}\right\},
$$

subject to

$$
\begin{gathered}
\rho \in\{0,1\} \\
q_{u}=\frac{q(1-p)}{q(1-p)+(1-q)} \\
\widetilde{w}=w_{g}-w_{u}
\end{gathered}
$$




$$
\begin{gathered}
u\left(w_{g}\right)+V_{t+1}\left(\pi_{g}, 1\right) \geq V_{t}^{m}(k, 1) \\
u\left(w_{u}\right)-\rho A(\widetilde{w})+V_{t+1}\left(\pi_{u}, q_{u}\right) \geq V_{t}^{m}\left(k, q_{u}\right) \\
p q\left(p-w_{g}+\pi_{g}\right)+(1-p q)\left(p q_{u}-w_{u}+\pi_{u}\right)-(1-\rho) \min \{p q, 1-p q\} k \geq \pi,
\end{gathered}
$$

where

$$
V_{t}^{m}(k, q)=\max _{w, \pi}\left\{\begin{array}{c}
u(w)+V_{t+1}(\pi, q) \\
\text { s.t. } \quad p q-w+\pi \geq k
\end{array}\right\},
$$

is the maximal utility obtainable in the market by a pool of workers of quality $q$.

We comment on this optimization problem.

The variable $\pi$ can be seen as the agent's level of debt minus his level of assets. ${ }^{37}$ The lifetime utility of a given worker is indeed increasing in the net present value of payments he is entitled to with the actual firm. And there is a one-to-one relationship between the net present value of payments and the expected profits the firm is able to generate with a worker of quality $q$.

Equation $[q]$ is the Bayes' rule (1) for the average quality of the workers of still unknown type.

Equation $[\alpha]$ computes the difference between the wage $w_{u}$ of workers of unknown type in the firm and the workers of good type. This difference is the source of the social preferences disutility (thus, cost for the firm).

Equations $[u]$ and $[g]$ are the participation constraints of, respectively, workers of type $u$ and $g$. The L.H.S. is simply the utility of accepting the proposed contract. The R.H.S. is the utility derived from the market wage. This market wage results from the zero-profit condition for the highest-bidding entrant.

For good workers $(q=1)$, the market wage is very easy to compute. We have

$$
V_{t}^{m}(k, 1)=\max _{w, \pi}\left\{\begin{array}{cc}
u(w)+V_{t+1}(\pi, 1) \\
\text { s.t. } & p-w+\pi \geq k
\end{array}\right\} .
$$

It is easy to see that the problem for good workers is fully stationary. In this case, the market contract consists of a constant wage $w_{t, g}^{*}=p-\frac{k}{T+1-t}$. Indeed, when $q=1$, there is no further heterogeneity in the pool, and hence $V_{t}(\pi, 1)=V_{t}^{m}(\pi, 1)$ for all $\pi, t$. Then, $V_{t}(\pi, 1)$ is a decreasing, strictly concave, and differentiable function, with ${ }^{38}$

$$
-\frac{\partial}{\partial \pi} V_{t}(\pi, 1)=u^{\prime}\left(p-\frac{\pi}{T+1-t}\right),
$$

which leads to the expression for the wage. Problem (7) is the natural generalization of this argument for a generic worker of still unknown type. Since when a worker decides unilaterally (deviates) to leave the firm, he will not be entitled to any payment from the old firm and the new firm will make zero expected profits, his level of debt is precisely $k$, the cost he will have to pay when changing firm.

We now explain the constraint $[\rho]$. In our context, firms offer long-term contracts and face competition by entrants. Thus, a firm that keeps workers of the same type together faces a cost due to workers' social concerns. On the other hand, firms are somewhat shielded from competition (thus pay slightly lower wages) because of the moving costs that a competitor needs to pay in order to steal new workers. Hence, keeping workers in the firm is a matter of choice, and the variable $\rho$ models this choice. The main trade-off here is between the cost (higher wages)

37 For a similar interpretation of the state variable in a repeated moral hazard framework, see Green (1987)

38 See Appendix C, available online at http://www restud com/supplementary asp 
generated by social concerns and the benefit (lower wages) arising from the hiring cost. In principle, a firm might want to let go either the good types, or the unknown types, or both, depending on the circumstances. ${ }^{39}$ We show in Appendix A that the firm always fires the workers from the smaller-sized pool (either the good or those of yet unknown type), and thus one can formulate the problem with only one $\rho$ that keeps track of whether somebody is fired at all.

Constraint $[\pi]$ guarantees that with the proposed wage contract, the firm can secure expected profits at least equal to $\pi$. The values $p-w_{g}$ and $p q_{u}-w_{u}$ represent the present flow of profits the firm derives from the worker under the different contingencies, while $\pi_{z} z \in\{u, g\}$ represents the expected present value of profits the firm will make from next period onwards with the present worker. Recall that $\pi$ can be interpreted as the level of debt of the agent minus his level of assets. The future levels of profits $\pi_{z}$ can thus also be understood as the level of (contingent) debt the worker brings into the next period. In this sense, the constraint $[\pi]$ also plays the role of a law of motion for our state variable. The last component of the L.H.S. of the constraint indicates the payment of the moving costs, which occurs only when a group of workers leaves the firm. The "min" operator captures the fact that efficient worker flows affect only the least numerous group.

The equivalence result. The following result guarantees that we can solve for an equilibrium of the game in Section 2 by characterizing the solution to the optimization problem defined above. Besides, existence of the equilibrium is guaranteed.

Proposition 1 (recursive equivalence). An equilibrium of the game described in Section 2 always exists. Let the policy functions $\mathcal{O}(0, \lambda)=\left\{w_{t}, \pi_{t}, \pi_{z, t}, w_{z, t}, \rho_{t}\right\}_{z=g, u ; t=1, \ldots, T}$ and the value functions $\mathcal{V}(0, \lambda)=\left\{V_{t}, V_{t}^{m}\right\}_{t=1, \ldots, T}$ be a solution to the maximization problem described in Section 3 when $\pi_{1}=0$ and $q_{1}=\lambda$. Then, in any undominated equilibrium $[\mathcal{W}, \mathcal{F}, \mathbf{U}, \mathbf{w}, \overline{\mathbf{w}}]$ of the game, the wage offers, retention policies $\rho$ and pay-offs of all workers (except for at most a measure zero set of them) are given by $\mathcal{O}(0, \lambda)$ and $\mathcal{V}(0, \lambda)$ in the natural way.

At this equilibrium, the ex-ante utility of a worker belonging to a reference group of average quality $q$ is $\mathbf{E}\left[U_{t}\left(h_{t}\right) \mid h_{t-1}\right]=V_{t}(\pi, q)$.

\section{OPTIMAL CONTRACTS: THE RESULTS}

\subsection{The case without social preferences}

We aim to understand the effect of social preferences on the allocation of workers to firms and on the wage profiles. For this purpose, we first describe the predictions of our model in the absence of social concerns, that is, when $A \equiv 0$. In this case, the model extends Harris and Hölmström (1982) (HH hereafter) to a setting with mobility costs $k \geq 0$. The case when $k=0$ is a discrete support of human capital levels version of $\mathrm{HH}$.

Denote by $w_{z, t}$ the wage at period $t$ of a worker of type $z \in\{g, u\}$. Then:

Proposition 2 (no social preferences). Assume that there are no social concerns $(A \equiv 0)$.

(i) when $k=0$, the firm-worker assignment is indeterminate;

(ii) when $k>0$, no worker ever leaves his initial employer, that is, the optimal retention policy is $\rho_{t}=1$ for all $t$;

39 For example, the cost due to social concerns varies with workforce composition By taking different decisions as to which type of workers leave, one can modify the workforce composition and, thus, change this cost 
(iii) for all $k \geq 0$, the wage schedule is downward rigid, that is, $w_{z, t+1} \geq w_{z, t}$ for all $t$ and $z \in\{g, u\}$

(iv) wages are stationary for a given type, that is, $w_{z, t+1}=w_{z, t}$ for all $t$, and $z \in\{g, u\}$.

For very large levels of $k$, the market pressure is so low that the firm can fully insure the workers and pay them their expected productivity each period, that is, $w_{t}\left(h_{t}\right)=\lambda p$ for each equilibrium history $h_{t}$. For more moderate levels of moving costs (including $k=0$ ), the model generates monotone (downward rigid) wages. In period 1, each worker is paid less than his expected productivity, and the wage remains constant until the worker is revealed to be good. When the worker's type is revealed, he will be approached by an external firm, and his wage within the original firm must increase to match the market offer. His wage remains constant from that period onwards. Notice that when $k>0$, there are neither quits nor lay-offs, and when $k=0$, worker flows are indeterminate.

\subsection{The case with social preferences and without mobility costs}

From now on, we consider the case with social preferences, that is, $A(x)$ strictly increasing when $x>0$. When $k=0$, we have a full segregation result, that is, there will be no workers' heterogeneity within the same firm, and all wage dispersion is between firms.

Proposition 3 (skill segregation). If $k=0$, then the optimal retention policy is $\rho_{t}=0$ for all $t$, that is, firms hire from only one skill pool. The intra-firm wage dispersion is zero, while the inter-firm wage dispersion is maximal and identical to the case without social preferences described in Proposition 2 (for the case $k=0$ ).

In the absence of mobility costs, segregating the workforce saves on the pecuniary externality created by competitive pressures and the presence of social concerns within firms. In other models that produce segregation, this is driven by a direct externality over others' attributes. ${ }^{40}$ Agents, say, have preferences over the types of others. Here, preferences are only indirectly affected by the types of others, as the primary externality is induced by economic outcomes (which, in turn, are shaped by differences in type productivity and competitive pressures).

A corollary of this result is that worker compensation in this framework has the same structure as in HH. The good type, which has completely revealed his type, receives his expected productivity. For the other type, compensation is downward rigid and trades off the insurance concern of the risk-averse agents with the competitive pressure. Insurance creates a tendency to have constant wages. But since workers are free to move between firms, the good types necessarily have to be compensated when they reveal their type. The key difference with respect to $\mathrm{HH}$ is that here some workers actually leave the firm, that is, this model produces worker flows. In addition, notice that social preferences imply that in this extreme case all the observed wage dispersion is between firms. Within firms, instead, all workers receive the same wage.

Finally, notice that if those who leave are not the good types, they might be entitled to a compensation that is higher than their expected productivity. Since the new firm does not pay a wage in excess of expected productivity, the difference is made up by the former employer, in the form of severance payments. ${ }^{41}$

40 Seminal works in this area are Becker (1957) and Schelling (1971)

41 The presence of severance payments allows the firm to pay smaller wages during the employment period In this way, one can reinterpret this payment (and the lower wages in the past) as an optimal unemployment insurance scheme (see Hopenhayn and Nicolini, 1997; and Pavoni, 2004) 


\subsection{The general case}

We now consider the general case with both social concerns and mobility costs. To the previous assumption that $A(x)$ is strictly increasing when $x>0$, we now add the assumption that $k>0$. The introduction of frictions in the form of mobility costs creates a trade-off. On the one hand, if workers are free to move, this generates a gain in efficiency by lowering the within-firm inequality (the only one workers care about). On the other hand, this same mobility entails a cost.

The optimal solution to this trade-off shapes the patterns of worker flows, the allocation of skills across firms and the wage policy within firms. We consider all these aspects in turn.

We first focus on the hiring and firing policies of the firm and the relationship of these policies with some macroeconomic features of the labour market. We then investigate in more detail the internal wage policy of the firm.

Hiring and firing policies of the firm. Lemmas 1 and 2 at the end of Appendix A describe the key characteristics of firm turnover and, as a consequence, of market flows. We first show (Lemma 1) that turnover only affects one group of workers (never both of them) at any given moment. That is, outflows from firms are composed of workers of the same type at any given point in time.

Notice, however, that the model allows for the possibility of both quits (for high-productivity workers) and lay-offs (for low-productivity workers), although both cannot occur contemporaneously. ${ }^{42}$ Interestingly, the model has sharp predictions both about the circumstances generating flows of one type or another and about the payments made by the firm in the different cases. Indeed, Lemma 2 states that in order to minimize moving costs, the firm always lets go the least numerous group of workers. In each period, the fraction of workers known to have high productivity is $p q$. These workers are those who leave the firm if and only if $p q<1 / 2$.

In this model, when there is turnover, all workers of the same time type (known or unknown productivity) of a given cohort either leave or stay together. This implies that, if taken literally, we capture only a particular kind of turnover: the one seen in massive reorganizations. However, this result is an artefact of several non-essential simplifying assumptions. There are only two types, time is discrete, and there is a continuum of workers. With more types and a finite number of workers, the norm would in fact be that just one (or very few) workers would reveal themselves as much better or worse than the average. Those individuals would be let go, or laid off with a severance package. ${ }^{43}$ In fact, in that (more natural but harder to analyse) kind of model, massive reorganizations would require some correlation in type revelation.

Proposition 7 in Appendix A fully characterizes the transfers made by the firm in each case. The interesting case is when the firm "fires" the workers of low productivity. In this case, the firm might decide to pay a severance payment transfer to low-productivity workers. The intuition for this result is simple. Low-type workers earn higher wages than their expected productivity would indicate, for insurance reasons. The firm's contract guarantees the worker a certain level of welfare. In some circumstances, it is efficient to fulfil this commitment by letting the worker go. But, since the market is unwilling to pay the worker more than his productivity, the former employer makes up the slack. ${ }^{44}$ On the other hand, when the firm suffers an outflow of workers of good type, no payment needs to be made.

42 In our model, all separations are efficient As in all such models, the definition of what is a "quit" or a "lay-off" is somewhat arbitrary We choose to denote by "lay-off" a separation that entails a lower wage in the new firm than in the old firm (as we discuss below, this wage cut in turn induces a severance payment because the firm has a commitment to smooth consumption variations) A similar convention is used in most other models of efficient separations (see, for example, McLaughlin, 1990)

43 Recall that the firm policy is to let the least numerous group of workers leave Notice too that lay-offs also include some would-be good workers (who have not yet revealed themselves as such)

44 In a sense, we might say that in order to "convince" the worker to leave, the firm takes care of the insurance part of the contract even after the worker leaves 
Finally, we investigate the dynamic dimension of worker flows. We argued above that the optimal resolution of the social concerns/moving costs trade-off implies that worker flows are generated when the wage dispersion within the firm is too high, compared with the level of labour market frictions. Our model naturally generates a monotone change in the balance between the two sides of the trade-off over time. The competitive pressure from the market decreases with the age of the worker, since the competing firms have shorter horizons to cover the training cost $k$. Most of the flows must thus occur at the beginning of the workers' labour market experience. ${ }^{45}$

Characteristics of partial segregation. Above, we investigated the nature and timing of worker flows. We now focus on the characteristics of skill segregation and firm composition when (unlike in Proposition 3) segregation is not complete.

In our model, "partial segregation" can occur when, for some periods, the firms do not experience worker outflows. This typically happens for large $t$, when market pressure ${ }^{46}$ is relatively low compared with the social concerns induced by wage dispersion. Firm-skill composition under partial segregation is hence characterized by two types of firms. One type of firm is homogeneous in terms of skills. It only employs high-productivity workers (who have been revealed to be good at the very beginning of their careers). In the same labour market, we also see firms with a mixed composition of workers (some with high and some with low expected productivity). Interestingly, workers revealed to be good early on (with $t$ small) are both more likely to leave their current firm and more likely to get paid a higher wage. ${ }^{47,48}$ A worker of high type hence tends to be paid more when he is in a firm of only good workers and less when he is in a mixed firm. This is true even after the full adjustment of his wage has happened (i.e. this is not due to the effect we call "gradual promotions", described later on). In other words, the model generates a pure firm effect on wages (i.e. in addition to the worker type and to all other observables), a feature that is consistent with a number of empirical findings (e.g. Abowd, Kramarz and Margolis, 1999; Davis and Haltinwanger, 1991 and the literature cited there).

Finally, the model also allows us to make some interesting comparative static predictions about the aggregate composition of workers' labour market outcomes. Lemmas 1 and 2 imply that in a labour market where skills are abundant (high $\lambda$ ), firms are less likely to let the good workers go, and a cohort of workers hired at the same time is likely to have an increasing average productivity through time (as the less productive among them are more likely to be laid off). The opposite happens when $\lambda$ is low.

\subsection{Wage dynamics}

We now turn to the wage policy of the firm. When not all costs are solved with massive worker flows, the model generates interesting novel "internal labour market features". In particular, the wage dynamics will optimally subsume this source of inefficiencies in three different ways, which we analyse in turn.

A side product of these dynamics is that wage changes, both at the top and at the bottom of the wage distribution, do not necessarily reflect changes in productivity. In other words, a change in productivity at the individual level is not a necessary condition to observe contemporaneous wage changes for this individual, in the presence of social concerns. This result could

45 Hazard rates for worker-firm separations are indeed decreasing with tenure/experience (see, for example, Cabrales and Hopenhayn, 1997) Notice, however, that this is compatible with other explanations, such as learning about worker-firm complementarity

46 In turn, inversely related to $k /(T+1-t)$

47 Recall that the wage of a worker who has been revealed to be of high productivity in period $t$ approaches $p-\frac{k}{T+1-t}$.

48 These workers can be called "fast trackers" 
not be obtained with more standard models of wage dynamics, which emphasize, for instance, technological complementarities.

High-wage dynamics. The first observational implication of frictions in our model is that the reaction (in terms of wage increases) to new positive information about workers will be more gradual than one would expect from pure market forces.

In the standard $\mathrm{HH}$ model (without social concerns), once a high-productivity type is revealed, wages are immediately and fully adjusted upwards; the wage scheme is flat from then on. Indeed, such a one-step wage increase is optimal from the point of view of inter-temporal smoothing of utility for this worker.

In the presence of social concerns, this one-step full wage increase need not be optimal any more, for two reasons. First, the cost of envy suffered by the low-wage workers increases with the size of the wage gap within their reference group. Second, we have assumed that the reference group within which social concerns are active is composed of co-workers who were recently in similar circumstances. For these reasons, a more gradual wage increase reduces the cost of envy. Indeed, after one period with different wages, the lucky workers "exit" the reference group of the low-wage ones. In this way, the envy costs created at every wage increase only last for one period. This creates the scope for reducing the cost of inequality by making the transitions more gradual. Of course, this cost reduction should be balanced by the loss in utility generated by the less smooth path of consumption for the lucky worker. ${ }^{49}$

The duration of this gradual transition towards the high wage depends, of course, on the dynamics of reference group recomposition. If, as we assume, workers increasing their relative wage exit the reference group of lower wage earners in just one period, the gradual wage adjustment takes only one period. Richer dynamic structures for the evolution of the reference group would lead to longer transitions. In particular, if rather than exiting the reference group within one period of a promotion, this outflow occurred at a more gradual pace, the gradual promotion would also be a smoother, longer-lasting, process.

We call this gradual promotions. This is a qualitatively new feature of the wage dynamics, where firms exploit an endogenous dimension of the workers' preferences, the reference group, which they manipulate through the reaction of wage patterns to output realizations.

Note that, taken literally, the equilibrium predicts a smooth wage increase over an extended period of time, rather than a wage increase following the revelation of a good type. This prediction requires that following the wage increase, the dynamics of the reference group unravel until the worker enjoying the wage increase does not cause envy to his former co-workers. ${ }^{50}$ Inside the firm, this wage increase would usually be associated with some redefinition of the job characteristics and/or conditions (e.g. a new office, a training course, new colleagues, different tasks, or committee appointments) that ensure this progressive disconnection from previous peers. This is why we refer to the smooth wage increase as a gradual promotion, even though promotions are not explicitly modelled but only implicit in the wage rise. ${ }^{51}$

This result obviously depends on our assumption about reference group composition. It would not hold under alternative assumptions. Suppose, for example, that a "large" wage increase, later

49 Otherwise, the optimal policy would imply an $\varepsilon$-adjustment immediately, followed by a full increase one period

50 In the present formulation of the model, we require that this happens in just two periods As we discussed previously, the model can be easily extended to smoother reference group dynamics

51 We refer the reader to Bernhardt and Scoones (1993) and, especially, Bernhardt (1995) for a formal model of promotions where the firm is envisioned as a hierarchy of layers, workers differ in their ability, and more able workers are more productive at higher hierarchy layers Assuming that skills are observable only by the current employer, and that firms decide both on wages and on promotions, these models predict delayed promotions-because the employer exploits this information asymmetry to his advantage 
associated with a transfer to a very different social environment within the firm (moving to corporate headquarters, instead of regional ones), would make an individual disappear immediately from the reference group, whereas a "smaller" increase without a site-changing promotion would make an individual remain in his former peers' reference group. Then we would not necessarily observe gradual promotions. But notice two things. First of all, a large wage increase per se is unlikely to help in reducing social concerns. Such a mitigation of social concerns must probably be generated by a new factor: for example, when an effective promotion must be accompanied by a task re-assignment. In this case, we could observe fast promotions and sizable wage increases. Although a complete analysis of such an extended model necessitates further research, it is likely that these "large" wage changes cum social promotions may be so costly that gradual promotions would still hold for not-too-large productivity increases. Furthermore, and perhaps more importantly, gradual promotions are a good explanation, within our model, for the observation of correlated wage increases (Baker, Gibbs and Hölmström, 1994), which are hard to reconcile with a pure learning model.

Notice that - as Proposition 2(iv) shows - this feature of the wage profile is generated in our model by social preferences, that is, it is not present in the model when $A \equiv 0$.

Denote by $w_{g_{t}, t+\tau}$ the wage at period $t+\tau$ of a worker revealed to be good at period $t$, where $\tau \geq 0$.

Proposition 4 (gradual promotions). If $\widetilde{w}_{t}>0$ and $\rho_{t}=1$ (i.e. both types of workers are kept together in the same firm at time $t$ ), then $w_{g_{t}, t+2}>w_{g_{t}, t+1}>w_{g_{t}, t}$, that is, the wage for a worker revealed to be good at time t increases gradually.

Remark 1. In the absence of gradual promotions, the wage for the $g$ (ood) type, once revealed, would be $w_{g_{t}, t^{\prime}}=p-\frac{k}{T+1-t}$, for all $t^{\prime} \geq t+1$, that is, it would be equal to his productivity, net of moving costs (distributed equally over the remainder of the working life). However, when gradual promotions occur, the wages are such that $w_{g_{t}, t+1}<p-\frac{k}{T+1-t}$, and $w_{g_{t}, t^{\prime}}>p-\frac{k}{T+1-t}$ for all $t^{\prime} \geq t+2$.

Low-wage dynamics. The presence of social concerns also affects the dynamics of wages for low-wage earners, as we examine below. Without social concerns, the wages are stationary for a given type, as we showed in Proposition 2(iv) above. With social concerns, instead, wages are not stationary in general. Proposition 4 already establishes this fact for high wages. We now show that non-stationarity also holds for low wages.

First, wages may increase in the absence of productivity changes for the low type. This is the result of two interacting forces: mobility costs and envy costs.

In the absence of mobility costs, but with social preferences, workers of different skills segregate themselves into different firms, as shown in Proposition 3. With mobility costs, instead, the perceived skills within firms may be heterogeneous. Because of competitive pressures, this heterogeneity gives rise to intra-firm wage differentials. These intra-firm wage differentials, in turn, give rise to envy costs for low-wage earners. To compensate for this loss of utility, the optimal wage schedule increases the wages of these individuals, even though their perceived productivity remains low. ${ }^{52}$ We call this effect productivity-unrelated wage increase, to denote an upward shift in wages not motivated by a productivity increase.

Compared with a situation without social preferences, this increase in the lower wages reduces the intra-firm wage differentials. Thus, social concerns add a new source of wage compression in addition to the one already derived from insurance.

52 Mechanically, the presence of envy costs increases the marginal utility of low-productivity workers in these states 
More formally,

Proposition 5 (productivity-unrelated wage increase). If at two successive dates $\rho_{t}=0$, $\rho_{t+1}=1$ (i.e. $g(\mathrm{ood})$ types are let go at time $t$, but both types are kept together in the same firm at time $t+1)$ and $\widetilde{w}_{t+1}>0$, then $w_{u, t+1}>w_{u, t}$. In particular, when social concerns are not active in the current period but are active next period, the next-period wage for workers of yet unknown type is larger than their wage in the current period.

A final observation regarding the dynamic pattern of wages is that they do not need to be monotone increasing, unlike in $\mathrm{HH}$, where wages are downward rigid. We find that wages can decrease and thus are downward flexible. The substantial reason for this decrease in wages is that the social concerns become weaker. This is the case when, for example, the newly discovered good types start to leave the firm. The reference group for wage comparison changes, and so do the social concerns that condition the wages that are paid. In the absence of such outflows, wage decreases can also arise following a reduction in intra-firm wage dispersion. This reduction in intra-firm wage dispersion, in turn, reflects a decrease in market pressure that arises because of a reduction in the available time span to recoup mobility costs by competitors.

We call this downward wage flexibility.

Proposition 6 (downward wage flexibility). Consider two successive dates with $\rho_{t}=1$, $\rho_{t+1}=0$ (i.e. both types are kept together in the same firm at time $t$, but $g($ ood $)$ types are let go at time $t+1$ ) and $\widetilde{w}_{t}>0$, or two successive dates with $\rho_{t}=\rho_{t+1}=1$ (i.e. both types are kept together in the same firm both at time $t$ and at time $t+1)$, and $\widetilde{w}_{t}>\widetilde{w}_{t+1}$. Then, if the constraint $[u]$ is not binding at period $t+1$, we have $w_{u, t+1}<w_{u, t}$.

The combination of the two propositions about productivity-unrelated wage increase and downward wage flexibility gives rise to a result of wage non-monotonicity for the low-wage earners. Notice that this volatility in wages is not connected with changes in productivity. All this productivity-free volatility arises because of the interplay of social concerns within firms together with the dynamic features of the labour market. These results give rise to testable implications and separate this model from more standard models of labour markets.

Corollary 1 (wage non-monotonicity). If social concerns are not active in periods $t-1$ and $t+1$ but are active in period $t$, the wage increases between $t-1$ and $t$, and then decreases between $t$ and $t+1$ for the workers of yet unknown type.

\section{A THREE-PERIOD MODEL WITH COMPARATIVE STATICS}

To gain insights into the workings of the model, we now compute the optimal wage schedule for a three-period version of the model. The purpose is to illustrate the results on gradual promotions, productivity-unrelated wage increase and downward wage flexibility. In addition, we show, by means of this example, how these and other features of the model depend on the key parameters, such as moving costs, productivity, and the stochastic structure of types.

In this example, the per-period material pay-offs of workers who receive a total wage $w$ are

$$
u(w)=\beta w-\frac{1}{2} w^{2},
$$

where $\beta>0$. In addition to these material pay-offs, workers experience disutility from the material pay-offs of co-workers. Social concerns are measured by

$$
A(\widetilde{w})=\alpha \widetilde{w},
$$


where $\widetilde{w} \geq 0$ measures the distance between own compensation and co-workers' compensation. This quantity is set to zero if own compensation is the highest among workers in the same reference group. The parameter $\alpha$ measures the strength of envy costs.

The workers live $T=3$ periods. At the beginning of period $t=1$, all workers are of the same type and thus receive an identical total wage $w_{1}$. At the end of period $t=1$, some workers are revealed to be good. Period $t=2$ wages differ across both types of workers. We denote by $w_{u}$ (respectively $w_{g}$ ) the total wage for workers of yet unknown type (respectively revealed to be good) at the beginning of period $t=2$. At the end of period $t=2$, again, some more workers are revealed to be highly productive, and different workers receive different wages accordingly at $t=T=3$. Workers who were revealed to be good at the end of period $t=1$ receive $w_{g g}$. Workers recently revealed as good (end of period $t=2$ ) receive $w_{u g}$. Finally, workers still of unknown type at the last period receive $w_{u u}$.

Altogether, the wage schedule consists of six wages, $\mathbf{w}=\left\{w_{1}, w_{u}, w_{g}, w_{u u}, w_{g g}, w_{u g}\right\}$.

Besides computing optimal wages, firms also decide on their retention policies. That is, at the end of periods $t=1,2$ and after types have been revealed, firms can decide to keep the workers that have just been revealed to be good, or not to keep them. ${ }^{53}$ We set $\rho_{t}=1$ (respectively $\rho_{t}=0$ ) when those workers are kept within the firm (respectively quit the firm) at the end of period $t$.

We denote by $\rho=\left(\rho_{1}, \rho_{2}\right) \in\{0,1\}^{2}$ the corresponding vector capturing these binary decisions.

The optimal firm policy is thus an eight-vector $(\mathbf{w}, \rho)$, which we compute using the algorithm described in Appendix D. ${ }^{54}$

Numerical application. In what follows, we discuss a numerical implementation of the algorithm described in Appendix D. We compute the optimal values for the eight-vector $(\mathbf{w}, \boldsymbol{\rho})$ for a grid of values for the parameters $p, k, \lambda$ of the model. For our numerical exercise, we set $\beta=5^{55}$ and $\alpha=0 \cdot 1 .^{56}$ We perform the simulations for $T=3$ periods. Note that our recursive characterization of the equilibrium can be implemented numerically for any arbitrary finite number of periods $T$, but the three-period case is already rich enough to display a number of interesting phenomena without blurring the underlying intuition. ${ }^{57}$ Figures $1-3$ plot the results from this numerical implementation and illustrate the effects of the parameters $p$ and $k$.

Figure 1 plots $w_{g g}-w_{g}$ and $\rho_{1}$ against $k$ for different values of $p$ and for $\lambda=0 \cdot 5 .{ }^{58}$ Recall that $w_{g g}$ (respectively $w_{g}$ ) is the wage received in period 3 (respectively in period 2) by the

53 Note, very importantly, that the retention policy, in general, need not affect only the $g$ (ood) types As discussed above, the optimal firm retention policy can also consist of lay-offs for the workers of yet unknown type However, in the numerical exercise we conduct, we choose the values of parameters ( $\lambda$ and $p$ ) so that only the $g$ (ood) types (if any) are affected by the retention policy The conditions guaranteeing this are derived from Lemma 2 in Appendix A We could derive similar numerical findings by analysing the alternative retention policy, which affects workers of yet unknown type

54 Appendix D is available online at: http://www restud com/supplementary asp

55 Given our utility function, pay-offs are an increasing function of wages for wages below the bliss point $\beta$ In our three-period model, the maximal expected utility per worker is $3 p \leq 3$ By setting $\beta=5$, we thus ensure that all wages in an optimal wage schedule lie in the increasing part of the utility function

56 This value is on the low end of the values estimated for this parameter in the literature- to our knowledge Cabrales and Charness (2004) report a value of $\alpha=0 \cdot 1$. Fehr and Schmidt (2000a) and Bellemare, Kröger and van Soest (2005) find larger values We use the low estimation for two main reasons First, we want to see whether the effects indeed appear even for low values of social preferences Second, the estimates appearing in the literature are obtained for data from laboratory experiments, with small stakes decisions They thus may not be robust to field data, which typically involve larger stakes

57 The three-period case is also easily replicated, and the code easily modified We have programmed the algorithm in Matlab The code is available at http://selene uab es/acalvo/MatlabPreferences html

58 The graph looks very similar for alternative values of $\lambda$, as long as the condition stated in Lemma 2 - that the good workers are the only ones affected by the retention policy-is met We discuss the (small) differences below 

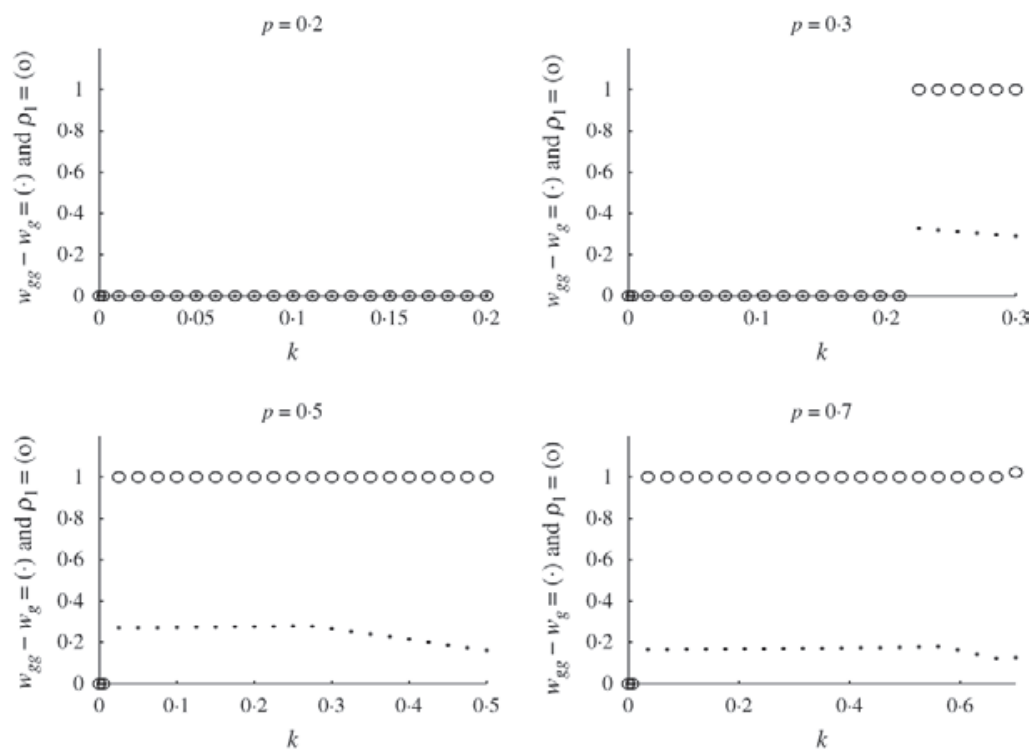

FIGURE 1

Gradual promotions and firing strategy of the firm The four panels display the firm optimal retention policy and the intertemporal wage increase between periods 2 and 3 for workers revealed to be good at the end of period 1, as a function of the moving cost, and for four values of the relative productivity

workers revealed to be good at the end of period 1 . The difference $w_{g g}-w_{g}$ thus corresponds to the wage increase experienced from period 2 to period 3 by these good workers. Absent the effect of social preferences that we call gradual promotions, this difference would necessarily be equal to 0 . Indeed, without social preferences, the optimal wage schedule consists of a one-period wage adjustment. With social preferences, instead, this difference can be strictly positive, reflecting the fact that $w_{g}$ does not match straightaway the productivity revealed by the good workers, which is then compensated by a higher wage increase in the next period, that is, $w_{g g}>w_{g}$. In this way, the firm takes advantage of the changing nature of reference groups.

As shown in Figure 1, gradual promotions only arise when the firm retains the high types (i.e. $\rho_{1}=1$ ), and there are wage differences across types of workers. Two conditions are needed for this. One condition is on $k$. The mobility cost must not take too low values, so that $\rho_{1}=1$ is indeed an optimal choice for the firm. On the other hand, $k$ should not be too large either, since otherwise market pressure is so low that there is no need to discriminate wages by revealed type. ${ }^{59}$ The other condition is that $p$ should not be too low, as it is never worthwhile keeping a small number of high-productivity workers who create a large dissatisfaction in all other coworkers, that is, in these cases we have $\rho_{1}=0$.

The binary variable $\rho_{1} \in\{0,1\}$ is clearly monotonic in $k$. This is intuitive. A large $k$ has the effect of reducing the market pressure, and hence wage dispersion, which in turn reduces the internal costs due to social preferences, and so the need for separations.

Figure 2 plots the wage difference between recently discovered high types and workers of yet unknown type, at the end of periods 2 and 3 . That is, we plot $w_{g}-w_{u}$ and $w_{u g}-w_{u u}$ as a function of the moving cost $k$ and for various values of $p$, for $\lambda=0.5$.

59 In the limit case, when $k$ is very large, $w_{g g}=w_{g}$ as there is no wage dispersion within the firm 

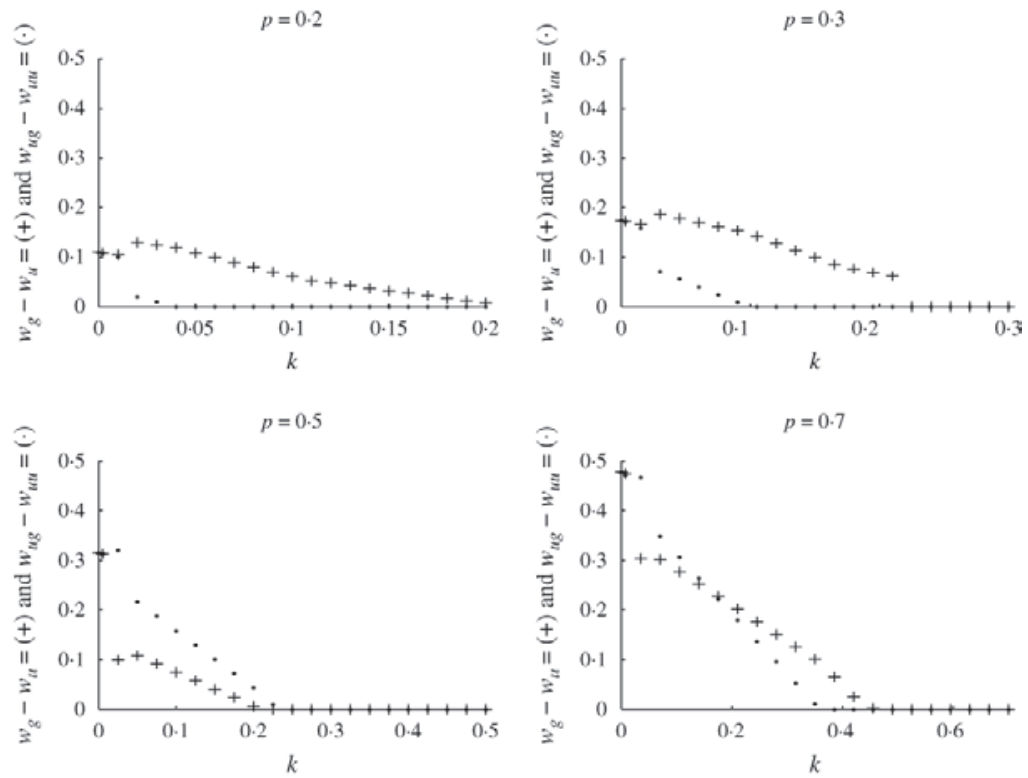

FIGURE 2

The four panels display the wage difference between good-type workers and workers of yet unknown type in periods 2 and 3 , as a function of the moving cost, and for four values of the relative productivity

The wage differences are typically decreasing with $k{ }^{60}$ The reason for this is intuitive. As $k$ goes up, the market pressure is lower, and hence the need for the current employers to discriminate between different types of workers is lower. For similar reasons, the market pressure increases with $p$, which represents the relative profitability of a high vs. a low type and so does the wage difference as depicted in the graph.

The wage dispersion can be of various sorts: within firms, across firms, or a mixture of both. We know from Figure 1 that when $p$ or $k$ is low, firms let all the good-type workers leave, that is, $\rho_{1}=0$. In these cases, the wage dispersion displayed in Figure 2 corresponds solely to inter-firm wage dispersion. All firms have a homogeneous workforce composition employed at a common wage, which differs across firms depending on their type composition. Looking at Figure 1 again, we see that wage dispersion need not arise within firms (at least during period 2) even when the good workers are retained, and the workforce composition is heterogeneous in types. Indeed, when $p=0.3$ and $k>0 \cdot 2$, both $\rho_{1}=1$ and $w_{g}-w_{u}=0$. For $p>0.3$, and low levels of $k$ instead, wage dispersion arises within firms even when different skills are mixed. In this latter case, gradual promotions and/or productivity-unrelated wage volatility are used to partially resolve the trade-off between the dislike for across-type wage inequality and the dislike for inter-temporal wage changes for a given worker.

Notice also that for $p=0.2$ and $p=0 \cdot 3$, we have $w_{g}-w_{u}>w_{u g}-w_{u u}$, whereas the opposite is true for $p=0 \cdot 5$, while the difference $\left(w_{g}-w_{u}\right)-\left(w_{u g}-w_{u u}\right)$ changes sign with $k$ for $p=0 \cdot 7$. The first effect that comes into play to explain these facts is that market pressure is

60 The graph only shows total wage dispersion In general, changes in dispersion affect both the low and the high wage 

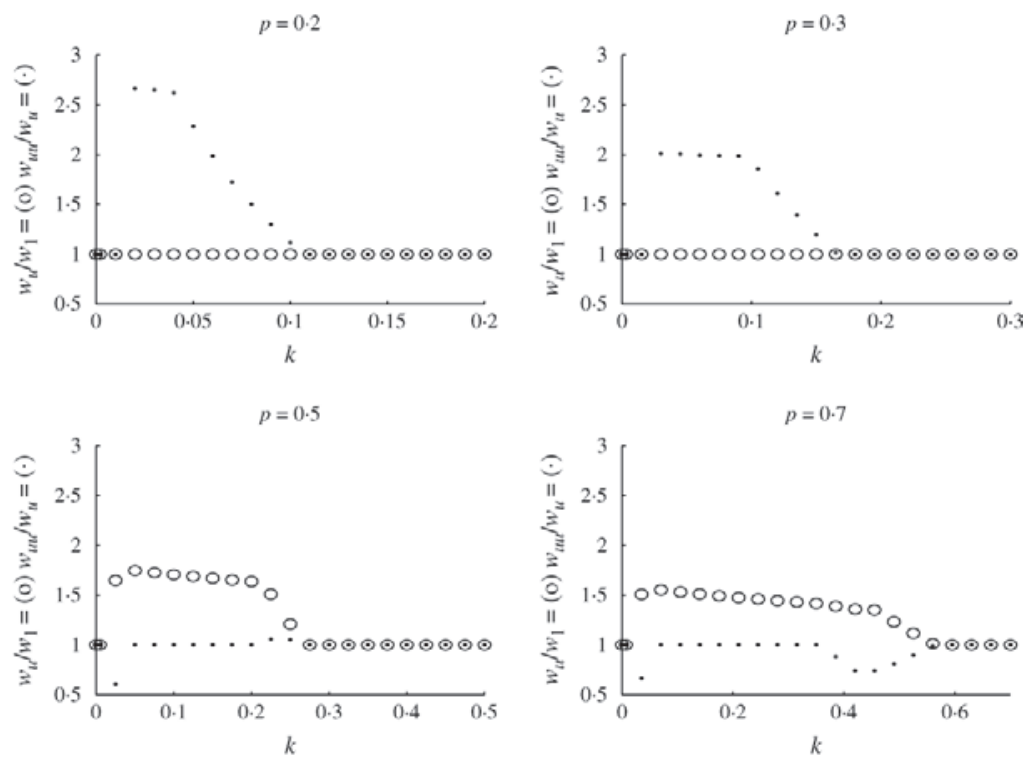

FIGURE 3

Productivity-unrelated wage volatility The four panels display the inter-temporal wage ratio for workers of unknown type, between periods 1 and 2, and between periods 2 and 3, as a function of the moving cost, and for four values of the relative productivity

larger in the second period than in the third (as there are more periods over which to spread the moving cost $k$ ). This tends to make $w_{g}-w_{u}$ larger than $w_{u g}-w_{u u}$. The second effect that comes into play is that for period 2 (but not for period 3), the firm can use gradual promotions to decrease the cost of envy. This makes $w_{g}$ lower and thus lowers $w_{g}-w_{u}$. When this effect is sufficiently strong, it can dominate the first one. Consistently with this explanation, Figure 1 shows that gradual promotions are used more heavily for $p=0.5$ than for $p=0.7$ (thus explaining why in Figure $2\left(w_{g}-w_{u}\right)-\left(w_{u g}-w_{u u}\right)$ is smaller for $p=0.5$ than for $\left.p=0.7\right)$.

Figure 3 plots the ratios $w_{u} / w_{1}$ and $w_{u u} / w_{u}$ against $k$ and for different values of $p$, for $\lambda=0 \cdot 7$. Recall that $w_{1}, w_{u}$, and $w_{u u}$ are, respectively, the wage of workers of unknown type at periods 1,2 , and 3 .

As with $w_{g g} / w_{g}$, absent the effect of social preferences, these ratios would be equal to one, and we would have neither productivity-unrelated wage increases $\left(w_{u} / w_{1}>1\right.$ or $\left.w_{u u} / w_{u}>1\right)$ nor downward wage flexibility $\left(w_{u u} / w_{u}<1\right)$. We can distinguish three cases.

First, there are situations where only Proposition 5 operates, and it does so only in period 3 (i.e. $w_{u} / w_{1}=1$ and $w_{u u} / w_{u}>1$ ). This happens when in the second period the good workers leave $\left(\rho_{1}=0\right)$, and thus $w_{u} / w_{1}=1$, while in the third period the good workers are retained $\left(\rho_{2}=1\right)$ because the mobility costs are higher (relative to the shorter horizon), and thus $w_{u u}>w_{u}$ due to the effect of social preferences. This situation arises when $p=0.2$ and $p=0.3$ and for not too high levels of $k$.

Second, there are situations where the low wage increases in both periods 2 and 3 (i.e. $w_{u} / w_{1}>1$ and $\left.w_{u u} / w_{u}>1\right)$. In this case, the market pressure is lower in the last period, and in fact the growth rate in that period is quite small. This suggests a new dynamic effect of social preferences on wages that we do not characterize in the propositions. This situation arises when $p=0 \cdot 5$, and for intermediate values of $k$, where $\rho_{1}=\rho_{2}=1$. 
In these first two situations, wages increase for individuals whose expected output in fact decreases. This coincides with a puzzling (for standard theories) empirical feature displayed by tenure on wage increase, and emphasized by Medoff and Abraham (1980) and Flabbi and Ichino (2001). We discuss this point below, in Section 6.

A third type of situation is one where both Propositions 5 and 6 operate, delivering the non-monotonicity result of Corollary 1 . This situation arises when $p=0.7$ and for intermediate values of $k$. For intermediate values of $k$, the mobility cost is already high enough such that market pressures do not bind in the third period, implying that $w_{u u}=w_{u g}=w_{1}$, while the very same market pressures still operate in the second period, and $w_{u} / w_{1}>1$. When $p=0.7$ for slightly lower values of $k$, market pressures operate both in the second and in the third period, but $\rho_{1}=\rho_{2}=1$. As can be seen in Appendix D, ${ }^{61}$ we then have $w_{u u}=w_{u}=w_{1}+\alpha$, so that $w_{u u} / w_{u}=1$. Notice, though, that this equality between the low wage in the second and third periods $\left(w_{u и} / w_{u}=1\right)$ is an artefact of linear social preferences in the example and would not hold more generally.

\subsection{Changes with a different value of $\lambda$}

When $\lambda$ is lower, $\rho_{1}=1$ is optimal for higher levels of $k$ than before. This is so since-from constraint $[\rho]$ - it is clear that when $\lambda$ is small it is less costly to let the good workers go. In terms of the firm's optimal retention policy, when the good workers are less numerous the envy of the workers of yet unknown type can be resolved by allowing only few good workers to leave the firm (and losing their expected discounted profit $k$ ). So, as discussed above, for low $\lambda$, that is, in a world where high skills are scarce, there are more worker flows in the economy. The "internal labour market" effects thus appear for higher values of $k$ (they move towards the right in the pictures). Total wage dispersion is hence higher, stemming mostly from higher betweenfirm wage dispersion made possible by the more intense worker flows, that is, there is more skill segregation. The opposite is true when $\lambda$ is larger.

\section{DISCUSSION}

One of the most well-accepted empirical findings is that wage increases are serially correlated through time, especially if associated with promotions or job changes (see Baker et al., 1994; and the discussion in Gibbons and Waldman, 1999, p. 1325). In our model, gradual promotions ${ }^{62}$ are a multiperiod response of wages to type revelation that naturally generates a strong serial correlation of wage increases within firms. ${ }^{63}$

A second implication of our model, which is different from Harris and Hölmström (1982), is that we can have real wage cuts. ${ }^{64}$ The fact that in $\mathrm{HH}$ wages are downward rigid is considered to be one of the major drawbacks of that model (e.g. see Gibbons and Waldman, 1999, p. 1347), because it is inconsistent with the substantial frequency of negative real-wage changes found by Baker et al. (1994). Moreover, our model makes a novel (empirically testable) prediction on wage cuts. They should typically be associated with changes in skill composition within firms. There is already some evidence in this respect, as Ierulli, Lazear and Meyersson Milgrom (2002) find that there is a correlation between turnover and both upward and downward wage mobility.

61 Appendix D is available online at: http://www restud com/supplementary asp

62 See Proposition 4 and Figure 1

63 In the absence of social concerns, the dynamics of wages in pure learning models such as Harris and Hölmström (1982) are mainly driven by the type revelation, which is independent across periods (a martingale) This alone would tend to generate uncorrelated wage increases However, downward wage rigidity generates some degree of correlation

64 See Proposition 6 and Figure 3 
Third, a key implication of our model is that wage changes need not be connected with productivity changes. Insurance motives would also disconnect wage movements from productivity movements, by dampening the impact of the latter in the former. However, in our model, the wage may increase even when worker expected productivity actually declines. ${ }^{65}$ This is because of the impact of firm workforce composition and market pressures on envy costs and their translation into optimal wage schedules. Medoff and Abraham (1980) and Flabbi and Ichino (2001) find that although worker performance ratings (a proxy for productivity) within the same job are slightly negatively related to experience, wages in fact increase with experience. This empirical fact is not easy to reconcile with theory using standard models (e.g. see Gibbons and Waldman, 1999, section V). ${ }^{66}$ Our model may thus rationalize such an apparent puzzle. And it suggests a new correlation: this kind of wage increase should be associated with an increase in the performance of the "reference" group. ${ }^{67}$

Field evidence suggests that organizations take into account equity concerns when hiring and firing. ${ }^{68}$ Our model also has implications for worker flows between firms and their implied changes in workplace skill segregation. As we explained in Section 4.3, in the presence of partial segregation, wages might display a pure firm effect. Thus, the dynamics of the labour market create a history dependence in the wage path that cannot be accounted for by tenure or actual worker's type. Workers who have been promoted early in their working life are more likely to be in homogeneous, higher-paying firms. ${ }^{69}$

Our simulation results show that the extent of skill segregation implied by the model decreases with mobility costs. ${ }^{70}$ This finding would allow us to explain part of the recent rise in inter-firm wage variance by an increase in segregation by skill, if there is a parallel change in mobility costs. Rhode and Strumpf (2003) document a secular decrease in mobility costs. ${ }^{71}$ Beyond reporting the sharp decrease of standard physical measures of mobility costs during the past century (such as physical transportation costs and communication costs), they also document a more recent decline in more intangible measures of mobility costs. This includes an increasing homogenization of the provision of public goods across counties in the U.S., as well as an increasing similarity of regional cultures and working practices (on the latter, see also the literature on the sociology of transnational processes, for example, Sassen, 1991, 1998). Other authors have also studied the impact of mobility costs on wage inequality from different perspectives. Lee and Wolpin (2006), for example, estimate a model of the U.S. economy that shows that mobility costs are substantial and are useful in explaining the observed wage structure.

Besides, our model suggests that the time-series evidence on skill segregation can be related to changes in labour market regulations (and organizational features) that affect mobility costs.

65 See Proposition 5 and Figure 2

66 Gibbons and Waldman (1999) (as well as HH) argue that the performance ratings used by Medoff and Abraham (1980) are not a good proxy for productivity For this reason, Flabbi and Ichino (2001) do the analysis also with other indicators of productivity (recorded absenteeism and misconduct episodes) and they obtain the same result

67 This is true even in the absence of technological externalities across members of the group, which would induce more standard team contract effects

68 For example, Bewley (1999, section 15 2) shows that firms are reluctant to hire overqualified applicants for morale reasons In section 137 , he shows that firms prefer to lay off workers rather than allowing them to stay for reduced pay Agell and Lundborg (1995) show that firms do not hire underbidders because they are perceived to be of lower quality and because hiring them would create internal inequities We found no evidence (for or against) our implications on sorting by skill This is not surprising, as the survey questions were designed specifically with existing theories in mind and to test why wage adjustment does not take economies to full employment

69 Moreover, as we pointed out earlier, one interesting empirical prediction of the model (shared with most models with some firm-specific capital and finite time horizons) is that employment hazard rates (out of the firm) decrease with experience or age of the worker

70 In particular, see how the probability of a worker flow $\left(\rho_{1}\right)$ changes with the cost of mobility $(k)$ in Figure 1 and how it affects wage dispersion in Figure 2

71 A (more indirect) measure of mobility costs can also be obtained from rates of labour turnover, which, as Mendez (2000) and Stewart (2002) show, have increased recently 


\section{CONCLUDING REMARKS}

This paper provides a new dynamic competitive equilibrium model of the labour market. The presence of social concerns and mobility costs has both cross-section and time-series implications for the market allocations of workers to firms, for within- and between-firms wage dispersion and for the internal wage structure of the firm.

In the previous section, we have shown that the model is consistent with a wide body of empirical evidence about labour markets. It also provides some new testable implications. There are some empirical findings we do not match. Some of them are due to the simplicity of our model and could be easily accounted for by adapting it with some simple extensions. For example, Baker et al. (1994) find what they call a "green-card" effect (see also Murphy, 1986). That is, they find that within the same job, expected wage increases are negatively correlated with the initial wage. We could account for this in our model by extending the gradual promotions result of Proposition 4, if we allowed for heterogeneities in social concerns across firms/plants or even worker groups. Recall that the total utility increase only depends on technological parameters, ${ }^{72}$ while the wage increase at the moment of promotion does depend negatively on the degree of social preferences (as the wage increases only by a fraction of the increase in productivity). Thus, it must be the case that social preferences shape the first increase in wage in the opposite direction to the second increase (see Remark 1 in Section 4.4). More precisely, the wage increase at the moment of promotion is obviously decreasing in the size of social concerns. If one looked at workers through time, the model would then predict that in plants or firms where social concerns are relatively low, entry wages for jobs at promotion start relatively high and then have relatively small further increases. The opposite would happen in firms with strong social concerns. Looking at a cross-section of workers, one would then find that high wages at promotions are negatively correlated with future wage increases.

Nominal wage rigidity (see, for example, Baker et al., 1994) and wide dispersion of total compensation (see Katz and Autor, 1999, section 2.3) are also well-documented features of worker compensation. An extended version of the model - which would allow for more informal forms of compensation and/or for a distinction between real and nominal variables-could generate such features if workers were more (socially) concerned about nominal wages than about real wages or other forms of compensation. This could be so, for example, since the latter have a lower degree of observability.

Another potential extension of our model would be one where efficiency required different types to be allocated to different tasks (i.e. jobs, à la Gibbons and Waldman, 1999, for example). In that extension, even in the absence of market pressure, there would be a "temporary" tension between the positive returns of promoting a worker, as required by efficiency, and the costs from the social concerns that the promotion would generate.

\section{APPENDIX A. PROOF OF PROPOSITION 1}

The aim of this appendix is to establish the equivalence between the original equilibrium problem with social preferences and workers' assignment decisions (the game of Section 2) and the recursive formulation in Section 3 We try to keep the exposition as readable for the non-technical reader as possible Notice, however, that the proofs of the remaining propositions, which are reported in Appendix B, can be fully understood without a careful reading of this appendix

Proof of Proposition 1 (recursive equivalence) The existence of a symmetric equilibrium $[\mathcal{W}, \mathcal{F}, \mathbf{U}, \mathbf{w}, \mathbf{w}]$ is established constructively by means of the recursive formulation Notice that a solution to the recursive problem exists since all objective functions are continuous and wage payments can be bounded below by 0 and above by 1 Profits can be bounded above by $T$ and below by $-T$, so as to have a compact choice set

72 It must reach $(T-t) u\left(p-\frac{k}{T+1-t}\right)$. 
We now use the optimal policy to construct an equilibrium of the game and show simultaneously existence and the equivalence result The functions $w_{t}(\cdot), \bar{w}_{t}(\cdot)$, and $U_{t}(\cdot)$ can be easily derived directly from the recursive formulation, in a way discussed in detail below By construction, the profit values derived by the policies are non-negative ex ante ${ }^{73}$ We now need to specify $\mathcal{W}$ and $\mathcal{F}$ The proposed equilibrium starts with all workers equally distributed among $M_{1}$ firms If at some date $t$ for some type $z$ we have $\rho_{z, t}=0$, then assume that all leaving workers get distributed equally among new firms $M_{t}$ and so on This equilibrium assignment can be generated by a $\mathcal{W}$ where all firms in a given period offer exactly the same contract, which specifies zero payments for all nodes emanating from an initial node with $f_{t} \neq j$, and the appropriate distribution of policies $\mathcal{F}$ so as to have an equal distribution among firms Finally, we complement the recursive policies by setting payments to zero at all nodes not reached in equilibrium The proof that such allocation constitutes an equilibrium will be divided into different steps

First, at period $t=1$, it is easy to see that undominated contract offers must be such that payments from firm $j$ are zero for each history $h_{1}$ such that $j \notin f_{1}([0,1])$ Hence, our assumption that only one firm makes non-zero payments at each $h_{1}$ can be made without loss of generality Then, standard arguments imply that $U_{1}\left(h_{1}\right)=V_{1}^{m}(k, \lambda)$, that is, worker payoffs at the beginning of the game correspond to the market threat In other words, a contract offer $W_{1}$ accepted in equilibrium by some worker solves the following problem: ${ }^{74}$

$$
V_{1}^{m}(\lambda, k)=\max _{w, \pi}\left\{\begin{array}{c}
u(w)+V_{2}(\lambda, \pi) \\
\text { s.t. } \quad p \lambda-w+\pi \geq k
\end{array}\right\},
$$

where the ex-ante utility $V_{2}(\lambda, \pi)$ corresponds to the $t=2$ version of the following problem:

$$
\begin{aligned}
V_{t}(q, \pi)= & \max _{\left\{w_{z}, s_{z}, \rho_{z}, \pi_{z}\right\}_{z}=u, g} p q\left\{\rho_{g}\left[u\left(w_{g}\right)+V_{t+1}\left(\pi_{g}, 1\right)\right]+\left(1-\rho_{g}\right) V_{t}^{m}\left(k-s_{g}, 1\right)\right\}+\text { (Problem 1) } \\
& +(1-q p)\left\{\rho_{u}\left[u\left(w_{u}\right)-\rho_{u} \rho_{g} A(\widetilde{w}(q))+V_{t+1}\left(\pi_{u}, q_{u}\right)\right]+\left(1-\rho_{u}\right) V_{t}^{m}\left(k-s_{u}, q_{u}\right)\right\}
\end{aligned}
$$

subject to

$$
\begin{gathered}
\rho_{z} \in\{0,1\}, z=u, g \\
q_{u}=\frac{q(1-p)}{q(1-p)+(1-q)} \\
\widetilde{w}=w_{g}-w_{u} \\
\rho_{u}\left[u\left(w_{u}\right)-\rho_{u} \rho_{g} A(\widetilde{w})+V_{t+1}\left(\pi_{u}, q_{u}\right)-V_{t}^{m}\left(k, q_{u}\right)\right] \geq 0 \\
\rho_{g}\left[u\left(w_{g}\right)+V_{t+1}\left(\pi_{g}, 1\right)-V_{t}^{m}(k, 1)\right] \geq 0,
\end{gathered}
$$

the non-negativity constraint $s_{z} \geq 0, z=u, g$, and the budget constraint

$$
p q\left[\rho_{g}\left(p-w_{g}+\pi_{g}\right)+\left(1-\rho_{g}\right)\left(-s_{g}\right)\right]+(1-p q)\left[\rho_{u}\left(p q_{u}-w_{u}+\pi_{u}\right)+\left(1-\rho_{u}\right)\left(-s_{u}\right)\right] \geq \pi .
$$

Recall that the timing is such that workers are paid at the beginning of the period while production occurs at the end of the period The function $V_{t}(q, \pi)=E\left[U_{t}\left(h_{t}\right) \mid h_{t-1}\right]$ hence represents the optimal ex-ante value of a unit mass of workers of average quality $q$ in a firm whose expected net present value (NPV) of profits related to this group is $\pi$.

Given $V_{2}(\pi, \lambda)$, the validity of problem (8) in an equilibrium outcome is immediate If the offer $\mathcal{W}$ were not utility maximizing, there would exist another offer with positive profits delivering a higher utility to all workers Some competitor would hence make this offer and attract these workers

73 Profits can be computed as follows Given the specified equilibrium, let

$$
\delta_{i}^{j}\left(h_{t}\right)=\left\{\begin{array}{ll}
1 & \text { if } h_{t} \text { is such that } f_{t}(i)=j \\
0 & \text { otherwise }
\end{array} .\right.
$$

Then, firm $j$ 's expected profits (the density) from worker $i$ at history $h_{t}$ are given by the following expression:

$$
\pi_{i}^{j}\left(h_{t}\right)=\mathbf{E}\left[\sum_{s=0}^{T-t}\left(\delta_{i}^{j}\left(h_{t+s}\right) y_{t+s}^{i}-w_{t+s, i}^{j}\left(h_{t+s}\right)\right) \mid h_{t}\right] .
$$

74 For simplicity, we assume that the initial set-up/hiring/training cost is $k$ 
We now describe how Problem 1 generates a symmetric equilibrium allocation Consider a history $h_{t}$, and consider the set of workers $i$ of average quality $q_{t}^{i}$ We denote by $\rho_{u}$ (respectively $\rho_{g}$ ) the symmetric equilibrium decision of all workers $i$ such that $y_{t}^{i}=0$ (respectively $y_{t}^{i}=1$ ) ${ }^{75}$ Consider, for example, a worker in this pool who was not revealed to be good yet Whenever $\rho_{u}=1$ (which implies that in $h_{t}^{i}$ we have $f_{t}(i)=f_{t-1}(i)$ ), this worker's ex-post utility in equilibrium is $U\left(h_{t}\right)=u\left(w_{u}\right)-\rho_{g} A(\widetilde{w})+V_{t+1}\left(\pi_{u}, 1\right)$ When $\rho_{u}=0$-and thus in $h_{t}^{i}$ we have $f_{t}(i) \neq f_{t-1}(i)$-his utility is $U\left(h_{t}\right)=V_{t}^{m}\left(k-s_{u}, 1\right)$. Ex-post utilities for workers with $q_{t}=1$ are defined similarly Obviously, the equilibrium payments $w_{t}\left(h_{t}\right)$ correspond to $w_{u}$ (respectively $w_{g}$ ) if in $h_{t}$ we have $q_{t} \neq 1$ (resp $q_{t}=1$ ) regardless of the specific firm entry $f_{t}$. And the profits values are the expected profits of firm $f_{t}$ at node $h_{t}$ regardless of the details of the other firms' offers

Whenever $\rho_{u}=1$ (respectively $\rho_{g}=1$ ), the constraint $[u]$ (respectively $[g]$ ) guarantees that the equilibrium value of utility $U\left(h_{t}\right)$ is such that the worker is not willing to unilaterally change firm When in equilibrium $\rho_{z}=1$, leaving the firm is an off-the-equilibrium behaviour; hence all firms not hiring this worker offer no payments at this node The worker "starts a new life" The argument made for $V_{1}^{m}$ in (8) implies that its market value satisfies

$$
V_{t}^{m}(k, q)=\max _{w, \pi}\left\{u(w)+V_{t+1}(\pi, q) ; \text { s t } p q-w+\pi \geq k\right\} .
$$

If the worker were never to leave the firm after $t-\rho_{g, s}=\rho_{u, s}=1$ for all $s \geq t$ - then the payments would always be made by only one firm and the equivalence between Problem 1 and the equilibrium would follow from standard arguments in the recursive contracts literature ${ }^{76}$

Now consider the problem related to $w_{u}, \pi_{u}$, and $s_{u}$, when $\rho_{u}=0$ (the case of $w_{g}, \pi_{g}$ and $s_{g}$ when $\rho_{g}=0$ is similar), and recall that the (total) wage $w_{t}\left(h_{t}\right)$ received in equilibrium by a worker $i$ with history $h_{t}=h_{t-1} \cup\left(0, q_{u}, f_{t}\right)$ can include some payment $w_{t}^{j}\left(h_{t}\right)$ from firm $j$ even though $f_{t}(i) \neq j$

We now argue that the unidimensional choice of $s_{u}$ suffices to fully describe such payments Since firms do not care about the timing of payments, $s_{u}$ may correspond to a lump-sum payment or to the NPV of a stream of payments spread across multiple periods and events Moreover, since firms take as given existing offers when making new ones, in equilibrium these new payments complete in an optimal way the pre-existing entitlements This implies that $V_{t}^{m}(k-$ $s_{u}, q_{u}$ ) must be the lifetime utility the worker can get from the market, given that all firms before $f_{t}$ committed to pay $s_{u}$ in expected NPV terms, independently of the form of such payments

The simplest interpretation of this is as follows When hired by a new firm, the worker brings with him his expected NPV of payments, which obviously corresponds to $s_{u}$ He transfers such entitlements to the firm, which then commits to a contingent plan of payments The transfer $s_{u}$ can hence be seen as the value of assets the worker is bringing with him Labour market competition over contracts occurs for this worker, who is hence the more attractive the higher is $s_{u}{ }^{77}$

In equilibrium, $s_{u}$ must obviously be chosen optimally If the stream of payments were not chosen to solve Problem 1, at the hiring moment (when firm $f_{t-1}$ made the offer, for example) it would have been possible to offer a better contract to the agent According to Problem 1, the optimal $s_{u}$ solves the following first-order condition: $-\frac{\partial V_{t}^{m}\left(k-s_{u}^{*}, q_{u}\right)}{\partial \pi}=\phi_{\pi}$, where $\phi_{\pi}$ is the Lagrãnge multiplier associated with constraint $[\pi]$ In turn, from the envelope and optimality conditions in (9), we have

$$
-\frac{\partial V_{t}^{m}\left(k-s_{u}^{*}, q_{u}\right)}{\partial \pi}=-\frac{\partial V_{t+1}\left(\pi_{t+1}^{*}, q_{u}\right)}{\partial \pi}=u^{\prime}\left(w_{t}^{*}\right) .
$$

The envelope condition and the first-order condition in period $t-1$ 's problem imply $\phi_{\pi}=u^{\prime}\left(w_{t-1}^{*}\right)$ where $w_{t-1}^{*}$ is the optimal level of the previous period In other words, the severance payment is chosen so as to allow perfect consumption-smoothing of the worker upon displacement The whole point of our recursive formulation and characterization results is to note that, through the severance payments, firms are able to internalize the wage losses (due to the moving cost $k$ ) of the worker in case of a transition across firms In this way, firms operate as planners, solving for a constrained efficient allocation We now show an intermediate proposition, which characterizes the behaviour of the severance payments

Proposition 7. Let $s_{z}^{*}, z=u, g$ be part of the optimal solution to Problem 1. If $\rho_{u}^{*}=0$, then $-s_{z}^{*}=p q_{u}-w_{t}^{*}+$ $\pi_{t+1}^{*}-k$, while if $\rho_{g}^{*}=0$, then $s_{g}^{*}=0$.

75 We drop the time subscript whenever this is not a source of confusion Notice that for a group such that $q_{t}=1$, that is, they were all revealed to be good in the past, the notation in Problem 1 is a bit redundant since $q=1$ is absorbing, and we obviously have $\rho_{t+n}=1, n \geq 0$ with constant wages as an optimal choice, due to the strong stationarity of the problem

76 The problem is a simple extension of Thomas and Worrall (1988) See also Ljungqvist and Sargent (2000)

77 We assume that from the moment a worker is revealed to be good, he stops receiving payments from any firm other than the one employing him at that date This is without loss of generality For a given set of wage offers from all other firms, the cheapest way for a firm to make attractive his contract with a promised future payment is to pay when outside wages are low (both by concavity and from social concerns) 
Proof. Recall the previous discussion From the definition of the market problem in (9), when $\rho_{u}^{*}=0$ the result is obtained by construction: $-s_{z}^{*}=p q_{u}-w_{t}^{*}+\pi_{t+1}^{*}-k .{ }^{78}$ We now show that the solution for $s_{g}$ must be at the corner whenever $\rho_{g}^{*}=0$ Notice, first of all, that when $\rho_{g}^{*}=0$ social concerns considerations disappear Recall again the above discussion and consider the wage and profits $w_{t}^{*}$ and $\pi_{t+1}^{*}$ the worker is entitled to by the market when $s_{g}^{*}>0$. Clearly, $u\left(w_{t}^{*}\right)+V_{t+1}\left(\pi_{t+1}^{*}, 1\right)=V_{t}^{m}\left(k-s_{g}^{*}, 1\right)>V_{t}^{m}(k, 1)$. Now consider the following allocation: set $\tilde{\rho}_{g}=1, \tilde{w}_{g}=w_{t}^{*}$, and $\tilde{\pi}_{g}=\pi_{t+1}^{*}$. This allocation would satisfy the participation constraint $[g]$, implying a wage for the good not greater than that for the unknown, that is, there would be no social concerns On the other hand, the net return of such allocation would be higher then $-s_{g}^{*}$ since $-s_{g}=p-w_{t}^{*}+\pi_{t+1}^{*}-k<p-w_{t}^{*}+\pi_{t+1}^{*}$ : the moving cost would indeed be saved We have obtained a contradiction It must hence be that $s_{g}^{*}=0 \quad \|$

Notice that the above result implies that a positive severance payment can only be paid in the case of a pool of workers of unknown type changing firm Although efficient separations do not allow us to make a sharper distinction, such a feature of the severance payments allows us to call "firing" the situation of a positive flow of workers of unknown type The fact that $s_{g}^{*}=0$, instead, allows us to denote as "quit" the situation when it is the pool of good workers that leaves the firm

We now continue our derivation of the proof Notice that whenever $\rho_{z}=1$ the optimal value for $s_{z}$ is indeterminate since it never appears in the objective function or in the constraints Symmetrically, whenever $\rho_{z}=0$ we get indeterminate values for $w_{z}$ and $\pi_{z}$. For later use, and with some abuse in notation, we can denote by $w_{z}$ and $\pi_{z}$ the value the agent obtains from the market after separation (for example, in the case discussed above for period $t$, we have $w_{u}=w_{t}^{*}$, and $\pi_{u}=\pi_{t+1}^{*}$, where $w_{t}^{*}$ and $\pi_{t+1}^{*}$ solve (10))

We have hence shown that the equilibrium allocation can be written in recursive form using Problem 1 As a further intermediate step, we now show that Problem 1 is equivalent to the following Problem 2:

$$
\max _{\left\{w_{z}, \pi_{z}, \rho_{z}\right\}_{z}=u, g} p q\left[u\left(w_{g}\right)+V_{t+1}\left(\pi_{g}, 1\right)\right]+(\text { Problem } 2)+(1-p q)\left[u\left(w_{u}\right)-\rho_{g} \rho_{u} A(\widetilde{w})+V_{t+1}\left(\pi_{u}, q_{u}\right)\right],
$$

subject to

$$
\begin{gathered}
\rho_{u}, \rho_{g} \in\{0,1\} \\
q_{u}=\frac{q(1-p)}{q(1-p)+(1-q)} \\
\widetilde{w}=w_{g}-w_{u} \\
u\left(w_{u}\right)-\rho_{u} \rho_{g} A(\widetilde{w})+V_{t+1}\left(\pi_{u}, q_{u}\right) \geq V_{t}^{m}\left(k, q_{u}\right) \\
u\left(w_{g}\right)+V_{t+1}\left(\pi_{g}, 1\right) \geq V_{t}^{m}(k, 1) \\
p q\left[p-w_{g}+\pi_{g}-\left(1-\rho_{g}\right) k\right]+(1-p q)\left[p q_{u}-w_{u}+\pi_{u}-\left(1-\rho_{u}\right) k\right] \geq \pi
\end{gathered}
$$

where

$$
V_{t}^{m}(k, q)=\max _{w, \pi}\left\{\begin{array}{c}
u(w)+V_{t+1}(\pi, q) \\
\text { s.t. } \quad p q-w+\pi \geq k
\end{array}\right\} .
$$

Proposition 8. Let $\left(w_{z}^{2}, \pi_{z}^{2}, \rho_{z}^{2}\right)$ be the solution to Problem 2. Assume that $\rho_{g}=\rho_{u}=0$ is never optimal. Then $\left(w_{z}^{2}, \pi_{z}^{2}, \rho_{z}^{2}\right)$ solves Problem 1 .

Proof. We will first show that $\left(w_{z}^{2}, \pi_{z}^{2}, \rho_{z}^{2}\right)$ solves Problem 1 on a case-by-case basis; we then show that the decisions over the $\rho \mathrm{s}$ are the same in the two problems

Case (i): $\rho_{z}=1$ for $z=u, g$. It is straightforward to see that both the objective functions, and the budget constraints of Problem 1 and Problem 2 are identical in this case Moreover, it is easy to see that when $\rho_{z}=1,[z]$ and $\left[z^{\prime}\right]$ are identical, for $z \in\{u, g\}$.

Case (ii): $\rho_{u}^{2}=0$ and $\rho_{g}^{2}=1$. Recall that the severance payment must be set to $-s_{u}^{1}=p q_{u}-w_{u}^{2}+\pi_{u}^{2}-k$. Then it is easy to see that the budget constraint in Problem 1 coincides with that of Problem 2 If we set $\rho_{u}^{1}=\rho_{u}^{2}=0$ in Problem

78 From its definition indeed $V_{t}^{m}\left(k-s_{u}, q_{u}\right)$ solves

$$
V_{t}^{m}\left(k-s_{u}, q_{u}\right)=\max _{w_{t}, \pi_{t+1}}\left\{\begin{array}{c}
u\left(w_{t}\right)+V_{t+1}\left(\pi_{t+1}, q_{u}\right) \\
\text { s.t. } \\
p q_{u}-w_{t}+\pi_{t+1} \geq k-s_{u}
\end{array}\right\} .
$$


1, the constraint $[u]$ disappears The participation constraints $\left[u^{\prime}\right]$ in Problem 2 are satisfied as well, since whenever $w_{u}^{2}=w_{u}^{1}$ and $\pi_{u}^{2}=\pi_{u}^{1}$, by construction $u\left(w_{u}^{2}\right)+V_{t+1}\left(\pi_{u}^{2}, q_{z}\right)=u\left(w_{u}^{1}\right)+V_{t+1}\left(\pi_{u}^{1}, q_{z}\right)=V_{t}^{m}\left(k-s_{u}^{1}, q_{u}\right)$ (just look at the definition of the market problem in footnote 78) Indeed, for all $z \in\{u, g\}$ we have $V_{t}^{m}\left(k-s_{z}, q_{z}\right) \geq V_{t}^{m}\left(k, q_{z}\right)$, where the last inequality derives from monotonicity of $V_{t}^{m}$ and the fact that $s_{z} \geq 0$

The (symmetric) Case (iii) $\rho_{u}^{2}=1$ and $\rho_{g}^{2}=0$ is straightforward, and the proof follows exactly the same lines as Case (ii).

It is now easy to see that $\left(w_{z}^{2}, \pi_{z}^{2}, \rho_{z}^{2}\right)$ solving Problem 1 becomes trivial, since the costs and returns of payments, and the trade-offs over the $\rho \mathrm{s}$ are the same in the two problems The reason is that whenever $\rho_{z}=0$, then $u\left(w_{u}^{2}\right)+$ $V_{t+1}\left(\pi_{u}^{2}, q_{z}\right)=V_{t}^{m}\left(k-s_{u}^{1}, q_{u}\right) \quad \|$

In order to obtain the final formulation in the main text, we need to show that $\rho_{u}=\rho_{g}=0$ can never be optimal for $k>0$, and to find out which group of workers is going to be fired Consider Problem 2

Lemma 1. If $k>0$, then $\left(\rho_{u}, \rho_{g}\right) \neq(0,0)$ in the optimal contract.

Proof. Notice that from the objective function and the participation constraints when $\rho_{z}=0$ then $\rho_{z^{\prime}} \neq z=1$ is weakly optimal But then from the budget constraint setting $\rho_{z^{\prime}}=1$ is strictly optimal as long as $k>0$. $\quad \|$

Lemma 2. If in the optimal contract $\rho_{u}+\rho_{g}=1$, then if $p q<1-p q$ then $\left(\rho_{u}, \rho_{g}\right)=(1,0)$, while if $p q>1-p q$ then $\left(\rho_{u}, \rho_{g}\right)=(0,1)$.

Proof. We saw above that when $\rho_{u}+\rho_{g}=1$ the only difference for the optimal choice is made by the budget constraint Hence the result comes immediately since when $p q<1-p q$ the good type is the less numerous one $\|$

These results complete the proof and lead to the expression in the main text $\|$

\section{APPENDIX B. PROOFS OF THE REMAINING PROPOSITIONS}

All proofs that follow will be based on the recursive formulation of the problem and the differentiability of the value function The properties of the associated value function $V_{t}$ are formally shown in Appendix $\mathrm{C}^{79}$

Proof of Proposition 2 (no social preferences). (i) and (ii) are straightforward (iii) and (iv) are the key results in $\mathrm{HH}$, whose proof fully applies here Here is the formal proof In the absence of social concerns, the problem can be written as follows:

$$
V_{t}(\pi, q)=\max _{w_{u}, w_{g}, \rho, \pi_{u}, \pi_{g}}(1-p q)\left[u\left(w_{u}\right)+V_{t+1}\left(\pi_{u}, q_{u}\right)\right]+p q\left[u\left(w_{g}\right)+V_{t+1}\left(\pi_{g}, 1\right)\right],
$$

subject to

$$
\begin{gathered}
\rho \in\{0,1\} \\
q_{u}=\frac{q(1-p)}{q(1-p)+(1-q)} \\
u\left(w_{u}\right)+V_{t+1}\left(\pi_{u}, q_{u}\right) \geq V_{t}^{m}\left(k, q_{u}\right) \\
u\left(w_{g}\right)+V_{t+1}\left(\pi_{g}, 1\right) \geq V_{t}^{m}(k, 1) \\
p q\left(p-w_{g}+\pi_{g}\right)+(1-p q)\left(p q_{u}-w_{u}+\pi_{u}\right)-(1-\rho) \min \{p q, 1-p q\} k \geq \pi .
\end{gathered}
$$

(i) When $k=0$, and from $[\pi]$, any retention decision $\rho \in\{0,1\}$ is optimal As a result, the market assignment of workers to firms is indeterminate

(ii) It is clear from constraint $[\pi]$ that as long as $k>0, \rho=1$.

(iii) Now take the first-order conditions and use the envelope condition to get

$$
u^{\prime}\left(w_{z}\right)=-\frac{\partial}{\partial \pi_{z}} V_{t+1}\left(\pi_{z}, q_{z}\right)=\frac{-\frac{\partial}{\partial \pi} V_{t}(\pi, q)}{1+\phi_{z}} \text { for } z=u, g,
$$

79 Appendix C is available online at http://www restud com/supplementary asp 
where $\phi_{z}$ is the Lagrange multiplier associated to constraint [z]. Since $\phi_{z} \geq 0$, wages are weakly increasing as stated in the first part of (iii) To see the second part of the statement, notice that the R H S in $[u]$ decreases with $t$. Hence $\phi_{u, t}=0$ for all $t$, and the result follows from the first-order conditions That is, a constant wage (as required by insurance motives) also solves the participation constraint

(iv) When in (11) $\phi_{g}>0$, we might have an increase in wage However, once the type is revealed, the problem for these workers becomes stationary \|

Proof of Proposition 3 (skill segregation) When $k=0$, the participation constraint $[g]$ is always binding (otherwise the firm could not make zero ex-ante profits); hence setting $\rho_{t}=1$ will induce social concerns Setting $\rho_{t}=0$ increases the objective function and relaxes constraint $[u]$ The segregation result derives from our assumption that only new firms hire, together with the fact that we focus on a symmetric equilibrium where all firms let the same type of worker go (As explained below, the symmetry assumption is only needed here because $k=0$.)

Proof of Proposition 4 (gradual promotions) Let $w_{g_{t}, t+\tau}$ be the wage at period $t+\tau$ for a worker revealed to be good at $t$, where $\tau \geq 0$

The first-order conditions in each period for $w_{g}$ and $\pi_{g}$ when $\rho_{t}=1$ are (recall that $\frac{\partial A^{\prime}\left(\widetilde{w}_{t}\right)}{\partial w_{g, t}}=A^{\prime}\left(\widetilde{w}_{t}\right)$ )

$$
\left\{\begin{array}{l}
u^{\prime}\left(w_{g_{t-1}, t}\right)\left(1+\phi_{g, t}\right)-A^{\prime}\left(\widetilde{w}_{t}\right)=\phi_{\pi, t} \\
-\frac{\partial}{\partial \pi_{g, t+1}} V_{t+1}\left(\pi_{g, t+1}, 1\right)\left(1+\phi_{g, t}\right)=\phi_{\pi, t}
\end{array}\right.
$$

and the envelope condition next period after a good realization is

$$
-\frac{\partial}{\partial \pi_{g, t+1}} V_{t+1}\left(\pi_{g, t+1}, 1\right)=\phi_{\pi, t+1} .
$$

Equation (12) implies that

$$
u^{\prime}\left(w_{g_{t-1}, t}\right)-\frac{1}{1+\phi_{g, t}} A^{\prime}\left(\widetilde{w}_{t}\right)=-\frac{\partial}{\partial \pi_{g, t+1}} V_{t+1}\left(\pi_{g, t+1}, 1\right) .
$$

Next, notice that when the type is revealed there are no social concerns since there will be no heterogeneity on the workers So (12) at $t+1$ after a good realization and (13) imply that

$$
\begin{aligned}
u^{\prime}\left(w_{g_{t-1}, t+1}\right) & =-\frac{\partial}{\partial \pi_{g, t+1}} V_{t+1}\left(\pi_{g, t+1}, 1\right) \\
& =u^{\prime}\left(w_{g_{t-1}, t}\right)-\frac{1}{1+\phi_{g, t}} A^{\prime}\left(\widetilde{w}_{t}\right),
\end{aligned}
$$

and the result follows since when $\widetilde{w}_{t}>0$ then $A^{\prime}\left(\widetilde{w}_{t}\right)>0 \quad \|$

Proof of Proposition 5 (productivity-unrelated wage increase) In Appendix $C$, ${ }^{80}$ we show that, despite the fact that the function is not always differentiable or concave, we can without loss of generality restrict attention to differentiable points We can hence apply the (local) Kuhn-Tucker theorem (under differentiability) to show existence and non-negativity of the multipliers 81

We will focus on interior contracts The necessary conditions for an interior optimum are (recall that $\left.\frac{\partial A^{\prime}\left(\widetilde{w}_{t}\right)}{\partial w_{u, t}}=-A^{\prime}\left(\widetilde{w}_{t}\right)\right)$

$$
\begin{gathered}
u^{\prime}\left(w_{u, t}\right)+\rho_{t} A^{\prime}\left(\widetilde{w}_{t}\right)=\frac{\phi_{\pi, t}}{1+\phi_{u, t}} \\
-\frac{\partial}{\partial \pi_{u, t+1}} V_{t+1}\left(\pi_{u, t+1}, q_{u, t+1}\right)=\frac{\phi_{\pi, t}}{1+\phi_{u, t}} .
\end{gathered}
$$

From the next-period envelope condition, we also get

$$
-\frac{\partial}{\partial \pi_{u, t+1}} V_{t+1}\left(\pi_{u, t+1}, q_{u, t+1}\right)=\phi_{\pi, t+1}
$$

80 Appendix $\mathrm{C}$ is available online at http://www restud com/supplementary asp

81 For the technical reader, notice that we are assuming that the Kuhn-Tucker constraint qualifications are satisfied A sufficient condition for the constraint qualifications is the Slater condition for the existence of a strict interior feasible contract 
Now since $\widetilde{w}_{t+1}>0, \rho_{t}=0$, and $\rho_{t+1}=1,(14)$ and (15) at $t+1$ and (16) imply

$$
\begin{aligned}
{\left[u^{\prime}\left(w_{u, t+1}\right)+A^{\prime}\left(\widetilde{w}_{t+1}\right)\right]\left(1+\phi_{u, t+1}\right) } & =-\frac{\partial}{\partial \pi_{u, t+1}} V_{t+1}\left(\pi_{u, t+1}, q_{u, t+1}\right) \\
& =u^{\prime}\left(w_{u, t}\right) .
\end{aligned}
$$

Since $A^{\prime}\left(\widetilde{w}_{t+1}\right)>0$ and $\phi_{u, t+1} \geq 0$, we have that $u^{\prime}\left(w_{u, t+1}\right)<u^{\prime}\left(w_{u, t}\right)$. The result hence follows from the strict concavity of $u \quad \|$

Proof of Proposition 6 (downward wage flexibility) The fact that $w_{u, t-1}<w_{u, t}$ follows from the proposition on productivity-unrelated wage increases We show that $w_{u, t+1}<w_{u, t}$ The first-order conditions for workers of unknown type (14) and (15) at periods $t$ imply that

$$
u^{\prime}\left(w_{u, t}\right)+A^{\prime}\left(\widetilde{w}_{t}\right)=-\frac{\partial}{\partial \pi_{u, t+1}} V_{t+1}\left(\pi_{u, t+1}, q_{u, t+1}\right) .
$$

The next-period envelope condition for an interior contract is

$$
u^{\prime}\left(w_{u, t+1}\right)+\rho_{t+1} A^{\prime}\left(\widetilde{w}_{t+1}\right)=-\frac{\partial}{\partial \pi_{u, t+1}} V_{t+1}\left(\pi_{u, t+1}, q_{u, t+1}\right) .
$$

Hence

$$
u^{\prime}\left(w_{u, t+1}\right)+\rho_{t+1} A^{\prime}\left(\widetilde{w}_{t+1}\right)=u^{\prime}\left(w_{u, t}\right)+A^{\prime}\left(\widetilde{w}_{t}\right) .
$$

When $\rho_{t+1}=0$, given that $\widetilde{w}_{t}>0$, then necessarily $u^{\prime}\left(w_{u, t+1}\right)>u^{\prime}\left(w_{u, t}\right)$. When $\rho_{t+1}=1$, given that $\widetilde{w}_{t}>\widetilde{w}_{t+1}$, we have, again, that $u^{\prime}\left(w_{u, t+1}\right)>u^{\prime}\left(w_{u, t}\right)$. The result then follows from the strict concavity of $u \quad \|$

Acknowledgements. We gratefully acknowledge the financial help from Barcelona Economics CREA, from Fundación BBVA, from the Spanish Ministry of Science and Technology, FEDER, under grants SEJ2006-11665-C02-00, SEJ2005-01481ECON, and BEC2002-2130, and CONSOLIDER-INGENIO 2010 (CSD2006-0016) The research assistance of Inés Moreno de la Barreda and Judith Payne, and the helpful comments of three anonymous referees and the editor, Maitreesh Ghatak, are also gratefully acknowledged The usual disclaimer applies

\section{REFERENCES}

ABOWD, J M , KRAMARZ, F and MARGOLIS, D N (1999), "High Wage Workers and High Wage Firms", Econometrica, 67, 251-333

ACEMOGLU, D (1999), "Change in Unemployment and Wage Inequality: An Alternative Theory and Some Evidence", American Economic Review, 89 (5), 1259-1278

ACEMOGLU, D (2002), "Technical Change, Inequality and the Labor Market", Journal of Economic Literature, 40, $7-72$

AGELL, J and LUNDBORG, P (1995), "Theories of Pay and Unemployment: Survey Evidence from Swedish Manufacturing Firms", Scandinavian Journal of Economics, 97, 15-29

AGELL, J and LUNDBORG, P (2003), "Survey Evidence on Wage Rigidity and Unemployment: Sweden in the 1990s", Scandinavian Journal of Economics, 105, 295-307

AKERLOF, G A and KRANTON, R E (2000), "Economics and Identity", Quarterly Journal of Economics, 115, 715-753

BAKER, G , GIBBS, M and HÖLMSTRÖM, B (1994), "The Internal Economics of the Firm: Evidence from Personnel Data", Quarterly Journal of Economics, 109, 881-919

DE BARTOLOMÉ, C (1990), "Equilibrium and Inefficiency in a Community Model with Peer Group Effects", Journal of Political Economy, 98, 110-133

BECKER, G (1957) The Economics of Discrimination (Chicago: University of Chicago Press)

BELLEMARE, S, KRÖGER, S and VAN SOEST, A (2005), "Actions and Beliefs: Estimating Distribution-Based Preferences using a Large-Scale Experiment with Probability Questions on Expectations" (IZA Discussion Paper No 1666 , Institute for the Study of Labor)

BÉNABOU, R (1993), "Workings of a City: Location, Education, and Production", Quarterly Journal of Economics, 108, 619-652

BERNHARDT, D (1995), "Strategic Promotion and Compensation", Review of Economic Studies, 62, 315-339

BERNHARDT, D and SCOONES, D (1993), "Promotion, Turnover, and Preemptive Wage Offers", American Economic Review, 83, 771-791

BEWLEY, T F (1995), “A Depressed Labor Market as Explained by Participants”, American Economic Review Papers and Proceedings, 85, 250-254

BEWLEY, T F (1999) Why Wages Don't Fall during a Recession (Cambridge, MA: Harvard University Press) 
BLINDER, A and CHOI, D (1990), "A Shred of Evidence on Theories of Wage Stickiness", Quarterly Journal of Economics, 105, 1003-1015

BOLTON, G (1991), "A Comparative Model of Bargaining: Theory and Evidence", American Economic Review, 81, $1096-1135$

BOLTON, G and OCKENFELS, A (2000), "ERC: A Theory of Equity, Reciprocity and Competition", American Economic Review, 90, 166-193

BROWN, C and MEDOFF, J (1989), "The Employer Size Wage Effect", Journal of Political Economy, 97, $1027-1059$

BURGESS, S , LANE, J and MCKINNEY, K (2004), "Matching, Reallocation and Changes in Earnings Dispersion" (Mimeo, Bristol University)

CABRALES, A and CHARNESS, G (2004), "Optimal Contracts with Team Productions and Hidden Information: An Experiment” (Mimeo, University of California at Santa Barbara)

CABRALES, A and HOPENHAYN, H (1997), "Labor Market Flexibility and Aggregate Employment Volatility", Carnegie-Rochester Conference Series in Public Policy, 46, 189-228

CAMPBELL, C M , III and KAMLANI, K S (1997), "The Reasons for Wage Rigidity: Evidence from a Survey of Firms", Quarterly Journal of Economics, 112, 759-789

CHARNESS, G and RABIN, M (2002), "Understanding Social Preferences with some Simple Tests", Quarterly Journal of Economics, 117, 817-869

COLEMAN, J S (1990) Foundations of Social Theory (Cambridge, MA: Harvard University Press)

DAVIS, S and HALTINWANGER, J (1991), "Wage Dispersion between and within US Manufacturing Plants, 1963-1986", Brookings Papers on Economic Activity: Microeconomics, 115-200

VAN DIJK, F and VAN WINDEN, F (1997), "Dynamics of Social Ties and Local Public Good Provision", Journal of Public Economics, 64, 323-341

DUNNE, T, FOSTER, L , HALTIWANGER, J and TROSKE, K R (2004), "Wage and Productivity Dispersion in U S Manufacturing: The Role of Computer Investment", Journal of Labor Economics, 22 (2), 397-429

FEHR, E , KLEIN, A and SCHMIDT, K (2007), "Fairness, Incentives and Contractual Incompleteness", Econometrica, 75, 121-154

FEHR, E and SCHMIDT, K (2000a), "A Theory of Fairness, Competition and Cooperation", Quarterly Journal of Economics, 114, 817-868

FEHR, E and SCHMIDT, K (2000b), "Theories of Fairness and Reciprocity: Evidence and Economic Applications", forthcoming in M Dewatripont, L P Hansen, and S Turnovski (eds ) Advances in Economic Theory. Eighth World Congress of the Econometric Society (Cambridge: Cambridge University Press) 208-257

FERSHTMAN, C , HVIDE, H K and WEISS, Y (2006), "Cultural Diversity, Status Concerns and the Organization of Work", Research in Labor Economics, 24, 361-396

FLABBI, L and ICHINO, A (2001), "Productivity, Seniority and Wages: New Evidence from Personnel Data", Labour Economics, 8, 359-387

FRANK, R H (1984), “Are Workers Paid their Marginal Product?”, American Economic Review, 74, 549-571

FRANK, R H (1985) Choosing the Right Pond: Human Behavior and the Quest for Status (Oxford: Oxford University Press)

GIBBONS, R and WALDMAN, M (1999), "A Theory of Wage and Promotion Dynamics inside Firms", Quarterly Journal of Economics, 114, 1321-1358

GIBBS, M (1996), "Promotions and Incentives" (Mimeo, GSB University of Chicago)

GREEN, E J (1987), "Lending and Smoothing of Uninsurable Income", in E C Prescott and N Wallace (eds ) Contractual Arrangements for Intertemporal Trade (Minnesota: Minnesota Press) 3-25

GÜTH, W, SCHMITTBERGER, R and SCHWARZE, B (1982), "An Experimental Analysis of Ultimatum Bargaining", Journal of Economic Behavior and Organization, 3, 367-388

HARRIS, M and HÖLMSTRÖM, B (1982), "A Theory of Wage Dynamics", Review of Economic Studies, 49, 315-333

HOPENHAYN, H and NICOLINI, J P (1997), “Optimal Unemployment Insurance”, Journal of Political Economy, 105, $412-438$

IERULLI, K, LAZEAR, E P and MEYERSSON MILGROM, E E (2002), "Wage Changes in Sweden" (Mimeo, Stanford University)

JUHN, C, MURPHY, K M and PIERCE, B (1993), "Wage Inequality and the Rise in Returns to Skill", Journal of Political Economy, 101, 410-442

KATZ, L and AUTOR, D H (1999), "Changes in Wage Structure and Earnings Inequality", in O Ashenfelter and D Card (eds ) Handbook of Labor Economics (Elsevier) 1463-1555

KEYNES, J M (1936) The General Theory of Employment, Interest and Money (London: Macmillan)

KRAMARZ, F, LOLLIVIER, S and PELÉ, L -P (1996), "Wage Inequalities and Firm-Specific Compensation Policies in France", Annales d'Economie et de Statistiques, 41/42, 369-386

KREMER, M and MASKIN, E (1996), "Wage Inequality and Segregation by Skill" (NBER Working Paper No 5718, National Bureau of Economic Research)

LEDYARD, J O (1995), "Public Goods: A Survey of Experimental Research", in J H Kagel and A E Roth (eds ) Handbook of Experimental Economics (Princeton, NJ: Princeton University Press) 111-194

LEE, D and WOLPIN, K I (2006), "Intersectoral Labor Mobility and the Growth of the Service Sector", Econometrica, 74, $1-46$ 
LEGROS, P and NEWMAN, A (2002), "Monotone Matching in Perfect and Imperfect Worlds", Review of Economic Studies, 69, 925-942

LEGROS, P and NEWMAN, A (2004), "Beauty is a Beast, Frog is a Prince: Assortative Matching with Nontransferable Utilities" (Mimeo, University College London and Université Libre de Bruxelles)

LEVINE, D (1998), "Modelling Altruism and Spitefulness in Game Experiments", Review of Economic Dynamics, 1, 593-622

LJUNGQVIST, L and SARGENT, T J (2000) Recursive Macroeconomic Theory (Cambridge, MA: MIT Press)

MCLAUGHLIN, K J (1990), "General Productivity Growth in a Theory of Quits and Layoffs", Journal of Labor Economics, 8, 75-98

MEDOFF, J L and ABRAHAM, K G (1980), "Experience, Performance, and Earnings", Quarterly Journal of Economics, 95, 703-736

MENDEZ, R (2000), "Creative Destruction and the Rise in Inequality", Journal of Economic Growth, 7, 259-281

MURPHY, K J (1986), "Incentives, Learning, and Compensation: A Theoretical and Empirical Investigation of Managerial Labor Contracts", Rand Journal of Economics, 17, 59-76

PAVONI, N (2004), "Optimal Unemployment Insurance with Human Capital Depreciation and Duration Dependence" (UCL Discussion Paper No 03-08, http://www ucl ac uk/ uctpnpa)

RABIN, M (1993), "Incorporating Fairness into Game Theory", American Economic Review, 83, 1281-1302

REY-BIEL, P (2002), "Inequity Aversion and Team Incentives" (Mimeo, University College London)

RHODE, P W and STRUMPF, K S (2003), "Assessing the Importance of Tiebout Sorting: Local Heterogeneity from 1850 to 1990", American Economic Review, 93, 1648-1678

ROTH, A E (1995), "Bargaining Experiments", in J H Kagel and A E Roth (eds ) Handbook of Experimental Economics (Princeton, NJ: Princeton University Press) 253-342

SAINT-PAUL, G (2001), "On the Distribution of Income and Worker Assignment under Intra-Firm Spillovers, with an Application to Ideas and Networks", Journal of Political Economy, 109, 1-37

SASSEN, S (1991) The Global City: New York, London, Tokyo (Princeton, NJ: Princeton University Press)

SASSEN, S (1998) The Mobility of Labor and Capital: A Study in International Investment and Labor Flows (Cambridge: Cambridge University Press)

SCHELLING, T (1971), "Dynamic Models of Segregation”, Journal of Mathematical Sociology, 1, 143-186

SOBEL, J (2005), "Interdependent Preferences and Reciprocity", Journal of Economic Literature, 43 (2), 347-391

STEWART, J (2002), "Recent Trends in Job Stability and Job Security: Evidence from March CPS" (Working Paper No 356, Bureau of Labor Statistics)

THOMAS, J P and WORRALL, T (1988), "Self-Enforcing Wage Contracts", Review of Economic Studies, 55 (4), $541-554$ 